Supplement of Geosci. Model Dev., 13, 2073-2093, 2020

https://doi.org/10.5194/gmd-13-2073-2020-supplement

C Author(s) 2020. This work is distributed under

the Creative Commons Attribution 4.0 License.

(c) (1)

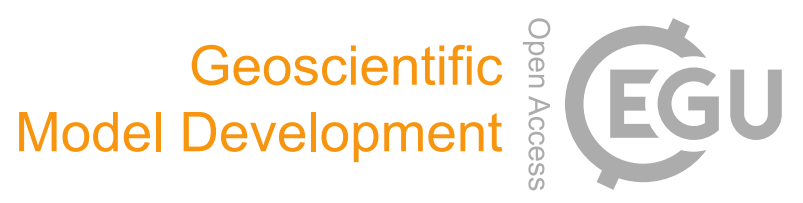

Supplement of

\title{
HR3DHG version 1: modeling the spatiotemporal dynamics of mercury in the Augusta Bay (southern Italy)
}

Giovanni Denaro et al.

Correspondence to: Alessandro Borri (alessandro.borri@iasi.cnr.it)

The copyright of individual parts of the supplement might differ from the CC BY 4.0 License. 


\section{S1 The Advection-Diffusion-Reaction Model - Seawater Compartment}

In the Section 3.1 of main text, the photochemical and biological redox reaction rate constants of $H g^{0}$ and $H g^{I I}$ use the parameterizations of Strode et al. (2007), with updates Soerensen at al. (2010). Specifically, the photochemical oxidation and photochemical reduction first-order rate constants $\left(k_{1}\right.$ and $\left.k_{2}\right)$ are directly proportional to the short-wave radiation flux (RAD)

5 at the sea surface attenuated by dissolved organic carbon (DOC) and pigments in the surface ocean $\left(C_{\text {pig }}\right)$ (Zhang et al., 2014; Soerensen et al., 2010; Qureshi et al., 2010; Batrakova et al., 2014). Also, the biological oxidation and biological reduction firstorder rate constants $\left(k_{3}\right.$ and $\left.k_{4}\right)$ are directly proportional to the organic carbon remineralization rate (OCRR) of the microbial reactions. Therefore, the photochemical and biological first-order rate constants are calculated as follows:

$$
\begin{aligned}
k_{1} & =k_{\text {photo-ox }} \cdot \operatorname{RAD}(z, t), \\
10 \quad k_{2} & =k_{\text {photo-red }} \cdot \operatorname{RAD}(z, t), \\
k_{3} & =k_{\text {bio-ox }} \cdot \operatorname{OCRR}(x, y, z, t), \\
k_{4} & =k_{\text {bio-red }} \cdot \operatorname{OCRR}(x, y, z, t),
\end{aligned}
$$

where $k_{\text {photo-ox }}$ and $k_{\text {photo-red }}$ are two constants reported by Soerensen at al. (2010) and according to Qureshi et al. (2010), $k_{b i o-o x}$ and $k_{b i o-r e d}$ are two constants estimated by Zhang et al. (2014) using the experimental findings of the $H g^{0}$ concentration and net evasion flux in the oceans. The short-wave radiation flux at the water surface $(R A D(0, t))$ is set up by using the remote sensing data (see the NASA web site http://eosweb.larc.nasa.gov/sse/RETScreen/). The RAD is assumed to decrease exponentially with the depth $z$, according to the Lambert-Beer's law, and to vary as a function of time $t$ due to the seasonal oscillations of the incident radiation flux $R A D(0, t)$. The organic carbon remineralization rate $(O C R R(x, y, z, t))$, is calculated within $\left(z<z_{0}\right)$ and out $\left(z>z_{0}\right)$ the euphotic zone as follows:

$\operatorname{OCRR}(x, y, z, t)=\frac{N P P(x, y, z, t)}{z_{0}} \cdot(1-\operatorname{peratio}(x, y, z, t)), \quad$ if $\quad z<z_{0}$

where NPP is the net primary production $\left[g C \cdot m^{-2} \cdot h^{-1}\right]$ obtained by the NP model, $z_{0}$ is the depth of euphotic zone $[m]$, peratio is the ratio of the particulate organic carbon concentration (POC) export to NPP out of the euphotic zone [dimensionless]. Since the bathymetry of the Augusta Bay indicates that the water column depth in the whole basin is less than the theoretical euphotic zone depth $\left(z_{0}=75 \mathrm{~m}\right)$ fixed by Zhang et al.(2014), in our model we use only the equation for $z<z_{0}$ (Zhang et al., 2014). Here, the NPP is calculated by using the conversion equation for $c h l$ a concentration (Baines et al., 1994), as follows:

$\log (N P P(x, y, z, t))=2.09+0.81 \cdot \log (\operatorname{chl} a(x, y, z, t))$,

where $\operatorname{chl} a$ is the chlorophyll concentration $\left[\mathrm{mg} \cdot \mathrm{m}^{-3}\right]$ obtained by the NP model (see Section S4).

On the other hand, the peratio is obtained by using the following equation (Zhang et al., 2014):

$\operatorname{peratio}(x, y, z, t)=-0.0081 \cdot T+0.0806 \ln \operatorname{chl} a(x, y, z, t)+0.426$,

where $T$ is the surface atmospheric temperature $[C]$ coming from remote sensing. 


\section{S1.1 Dissolved elemental mercury concentration}

\section{S1.1.1 Boundary conditions at the water-atmosphere interface - Dissolved elemental mercury concentration}

The mercury flux at the water-atmosphere interface $(\mathrm{z}=0)$ is obtained by both the River Model and Bagnato et al. (2013), as follows:

$$
\begin{gathered}
{\left.\left[D_{z} \frac{\partial H g^{0}}{\partial z}-v_{z} H g^{0}\right]\right|_{z=0}=W_{\text {etdep }} g^{0}-\phi_{G E M}=} \\
=\frac{H g_{g a s-a t m} \cdot P r}{\Delta t}+M T C_{\text {water-atm }} \cdot\left(H g_{\text {gas }-a t m}-\left.H \cdot H g^{0}\right|_{z=0}\right),
\end{gathered}
$$

where

- Wetdep $H g^{0}$ is the surface wet deposition flux of gaseous mercury concentration $\left[n g \cdot m^{-2} \cdot h^{-1}\right]$;

- $\phi_{G E M}$ is the surface evasion flux of elemental mercury concentration $\left[n g \cdot m^{-2} \cdot h^{-1}\right]$;

- $H g_{g a s-a t m}$ is the gaseous mercury concentration in the atmosphere as a function of time $[\mathrm{ng} / \mathrm{l}]$;

- $\operatorname{Pr}$ is the amount of precipitation as a function of time $[m]$;

- $\Delta t$ is the exposition time of the basin $[h]$;

- $M T C_{\text {water-atm }}$ is the gas phase overall mass transfer coefficient $[\mathrm{m} / \mathrm{h}]$;

- $H$ is the Henry's law constant [dimensionless].

45 The temporal behaviour of $\mathrm{Hg}_{\text {gas-atm }}$ is reproduced for one year by using the experimental data collected by IAS-CNR in 2011, and reported in a previous work (Bagnato et al., 2013). The dynamics of precipitations is obtained by using the remote sensing data on the average monthly precipitations in Augusta Bay (see the NASA web site http://eosweb.larc.nasa.gov/sse/RETScreen/). The $M T C_{\text {water-atm }}$ is calculated according to the River model (Ciffroy, 2015) as follows:

$M T C_{\text {water-atm }}=\frac{M T C_{\text {water-atm }, w} \cdot M T C_{\text {water-atm }, g}}{M T C_{\text {water-atm }, w}+H \cdot M T C_{\text {water-atm }, g}}$.

50 Here, the water film mass transfer coefficient $\left(M T C_{\text {water-atm,w }}\right)$ and the gas film mass transfer coefficient $\left(M T C_{\text {water-atm,g }}\right)$ are given by:

$M T C_{\text {water-atm,w }}=0.108 \cdot\left(u_{\text {wind }}\right)^{1.64} \cdot\left(\frac{P M_{\mathrm{CO}_{2}}}{P M_{\text {molar }}}\right)^{0.25}$,

$M T C_{\text {water-atm,g }}=864 \cdot\left(0.2 \cdot u_{\text {wind }}+0.3\right) \cdot\left(\frac{P M_{\mathrm{H}_{2} \mathrm{O}}}{P M_{\text {molar }}}\right)^{0.3}$,

55 where

- $u_{\text {wind }}$ is the wind speed $[\mathrm{m} / \mathrm{s}]$; 
- $\mathrm{PM}_{\mathrm{CO}_{2}}$ is the molar mass of carbon dioxide $[\mathrm{g} / \mathrm{mol}]$;

- $P M_{\text {molar }}$ is the molar mass of elemental mercury $[\mathrm{g} / \mathrm{mol}]$;

- $P M_{H_{2} O}$ is the molar mass of water $[\mathrm{g} / \mathrm{mol}]$.

60 The wind speed is obtained by averaging the values of annual mean wind speed of the last 15 years for the studied area (see the NASA web site http://eosweb.larc.nasa.gov).

The annual mercury evasion flux at the seawater-atmosphere interface $(\mathrm{V})$ is obtained by integrating the $\phi_{G E M}$ for the whole horizontal surface of the basin, and for the whole year. The annual atmospheric deposition of the elemental mercury is calculated by integrating the $\phi_{d e p}$ for the whole horizontal surface of the basin, and for the whole year.

\section{S1.1.2 Boundary conditions (lateral fluxes) - Dissolved elemental mercury concentration}

The lateral fluxes for all variables are set up equal to zero at the boundaries of Augusta basin (Valenti et al., 2017) except where inlets are localized. Moreover, we can neglect the elemental mercury flux at the water-sediment interface $\left(z=z_{b}\right)$. Therefore, we fix the following fluxes at the basin boundaries:

$$
\left[D_{x} \frac{\partial H g^{0}}{\partial x}-v_{x} H g^{0}\right]=\left[D_{y} \frac{\partial H g^{0}}{\partial y}-v_{y} H g^{0}\right]=\left.\left[D_{z} \frac{\partial H g^{0}}{\partial z}-v_{z} H g^{0}\right]\right|_{z=z_{b}}=0 .
$$

70 Since the direct $\mathrm{Hg}^{0}$ loads from rivers and sewerage are assumed to be negligible for the whole basin, we set:

$$
\begin{aligned}
& {\left[D_{x} \frac{\partial H g^{0}}{\partial x}-v_{x} H g^{0}\right]=I N P U T_{x_{\text {point-source }}}=\left.\left(\frac{Q_{\text {source }}}{A_{\text {source }}}\right)\right|_{x} \cdot H g_{\text {source }}^{0} \simeq 0,} \\
& {\left[D_{y} \frac{\partial H g^{0}}{\partial y}-v_{y} H g^{0}\right]=I N P U T_{y_{\text {point-source }}}=\left.\left(\frac{Q_{\text {source }}}{A_{\text {source }}}\right)\right|_{y} \cdot H g_{\text {source }}^{0} \simeq 0,}
\end{aligned}
$$

where

- $Q_{\text {source }}$ is the average flow rate of water at the point source $\left[\mathrm{m}^{3} / h\right]$;

- $A_{\text {source }}$ is the longitudinal section of the point source $\left[\mathrm{m}^{2}\right]$;

- $H g_{\text {source }}^{0}$ is the elemental mercury concentration of the point source $\left[\mu \mathrm{g} / \mathrm{m}^{3}\right]$;

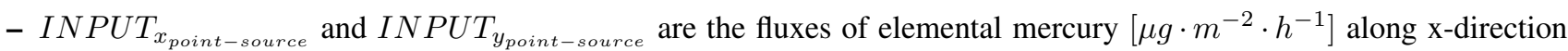
and y-direction, respectively, entering the basin from the point source.

80 The lateral fluxes at inlets (Scirocco and Levante) of the basin (Salvagio Manta et al., 2016) as a function of depth and time are given by:

$$
\begin{gathered}
\phi_{x_{\text {inlet }}^{0}}^{0}(z, t)=\left[D_{x} \frac{\Delta H g^{0}}{\Delta x}-v_{x_{\text {inlet }}}(z, t) \cdot H g_{\text {ext }}^{0}(z)\right]= \\
=\left[D_{x} \frac{\Delta H g^{0}}{\Delta x}+v_{x_{\text {inlet }}}(z, t) \cdot H g_{\text {int }}^{0}(z, t)\right],
\end{gathered}
$$




$$
\begin{gathered}
\phi_{y_{\text {inlet }}^{0}}^{0}(z, t)=\left[D_{y} \frac{\Delta H g^{0}}{\Delta y}-v_{y_{\text {inlet }}}(z, t) \cdot H g_{\text {ext }}^{0}(z)\right]= \\
=\left[D_{y} \frac{\Delta H g^{0}}{\Delta y}+v_{y_{\text {inlet }}}(z, t) \cdot H g_{\text {int }}^{0}(z, t)\right]
\end{gathered}
$$

85

where

- $v_{x_{\text {inlet }}}(z, t)$ is the absolute value of the marine currents velocity at the inlet along the $\mathrm{x}$-direction $[\mathrm{m} / \mathrm{h}]$;

- $v_{y_{\text {inlet }}}(z, t)$ is the absolute value of the marine currents velocity at the inlet along the y-direction $[\mathrm{m} / \mathrm{h}]$;

- $H g_{\text {int }}^{0}(z, t)\left(H g_{\text {ext }}^{0}(z)\right)$ is the internal (external) dissolved elemental mercury concentrations close to the inlet $\left[\mu g / m^{3}\right]$;

- $\Delta H g^{0}$ is the difference between the internal and external dissolved elemental mercury concentrations at the inlet of basin $\left[\mu g / m^{3}\right]$;

- $\phi_{x_{\text {inlet }}}^{0}(z, t)$ and $\phi_{y_{\text {inlet }}^{0}}^{0}(z, t)$ are the horizontal fluxes at the inlet $\left[\mu g \cdot m^{-2} \cdot h^{-1}\right]$.

The advection terms of Eqs. (S15)-(S16) are negative when the marine current velocities cause the external seawater to enter into the Augusta Bay, while they are positive when the marine current velocities cause the internal seawater to come out the basin.

The same boundary conditions (lateral fluxes) are also valid for $H g^{I I}, M e H g$ and $H g_{T}$. The annual net outflow of elemental mercury from basin to open sea is obtained by integrating Eqs. (S15)-(S16) for the whole lateral surface of the two inlets, and for the whole year. Similarly, the annual net outflows of $\mathrm{Hg}^{I I}$ and $\mathrm{MeHg}$ are calculated.

In order to perform the mass balance for the Augusta Bay, we calculate the annual net outflow of total mercury $(\mathrm{O})$ from the basin towards the open sea by considering both the spatio-temporal behaviour of total mercury concentration reproduced by the advection-diffusion-reaction model, and the marine currents velocities at the inlets calculated by the SHYFEM model (see Section S3).

\section{S1.2 Dissolved inorganic mercury concentration}

The dissolved inorganic mercury concentration as a function of depth $\left(H g^{I I}(z)\right)$ is obtained by solving Eq. (2). Since the sinking flux of the $S P M$-bound inorganic mercury $\left(S_{S P M}^{I I}\right)$ has to vanish at $z=0$ due to the condition of "cleaned" SPM entering through the seawater surface, in the Eq. (4) we fix the dissolved inorganic mercury concentration equal to zero at the seawater-atmosphere interface $\left(H g^{I I}(0)=0\right)$.

The annual amount of inorganic mercury removed by the suspended particulate along the water column (scavenging process) is obtained by integrating Eq. (4) on the whole 3D domain of the Augusta Bay. 


\section{S1.2.1 Boundary conditions at the water-atmosphere interface - Dissolved inorganic mercury concentration}

110 as follows:

$$
\left.\left[D_{z} \frac{\partial H g^{I I}}{\partial z}-v_{z} H g^{I I}\right]\right|_{z=0}=W e t d e p_{H g^{I I}}+\operatorname{Drydep}_{H g^{I I}}=\frac{H g_{a t m}^{I I} \cdot P r}{\Delta t}+\operatorname{Drydep}_{H g^{I I}}
$$

where

- Wetdep ${ }_{H g^{I I}}$ is the surface wet deposition flux of inorganic mercury $\left[\mathrm{ng} \cdot \mathrm{m}^{-2} \cdot \mathrm{h}^{-1}\right]$;

- Drydep $\mathrm{Hg}^{I I}$ is the surface dry deposition flux of inorganic mercury $\left[\mathrm{ng} \cdot \mathrm{m}^{-2} \cdot \mathrm{h}^{-1}\right]$;

- $H g_{a t m}^{I I}$ is the inorganic mercury concentration in atmosphere as a function of time $\left[\mathrm{ng} / \mathrm{m}^{3}\right]$;

- $\operatorname{Pr}$ is the amount of precipitation as a function of time $[m]$;

- $\Delta t$ is the exposition time of the basin $[h]$.

The time behaviour of the inorganic mercury concentration in atmosphere $\left(H g_{a t m}^{I I}\right)$ is reproduced for one year by using the experimental data collected reported in a previous work (Bagnato et al., 2013). The dynamics of precipitations is obtained by using the remote sensing data on the average monthly precipitations in Augusta Bay (see the NASA web site http://eosweb.larc.nasa.gov). The Drydep ${ }_{H g^{I I}}$ is set equal to that estimated by Rajar et al. (2007) for the whole Mediterranean basin (Rajar et al., 2007).

The annual atmospheric deposition of the inorganic mercury is calculated by integrating Eq. (S17) for the whole horizontal surface of the basin and for the whole year.

\section{S1.2.2 Boundary conditions at the water-sediment interface - Dissolved inorganic mercury concentration}

The inorganic mercury flux at the water-sediment interface $\left(z=z_{b}\right)$ is calculated as a function of time in each position $(\mathrm{x}, \mathrm{y})$ of the domain (River Merlin-Expo model, 2015):

$$
\left.\left[D_{z} \frac{\partial H g^{I I}}{\partial z}-v_{z} H g^{I I}\right]\right|_{z=z_{b}}=M T C_{\text {sed-water }}^{I I} \cdot\left(H g_{\text {pore-water }}^{I I}-\left.H g^{I I}\right|_{z=z_{b}}\right)
$$

where

- $M T C_{\text {sed-water }}^{I I}$ is the mass transfer coefficient for the inorganic mercury at the water-sediment interface $[m / h]$, which takes on a different value in each position $(\mathrm{x}, \mathrm{y})$ of the domain;

- $H g_{\text {pore-water }}^{I I}$ is the inorganic mercury concentration in the pore water of the shallowest layer of the sediment $\left[\mu g / m^{3}\right]$;

- $\left.H g^{I I}\right|_{z=z_{b}}$ is the dissolved inorganic mercury concentration in the deepest layer of the seawater $\left[\mu g / m^{3}\right]$; 
The annual benthic flux of inorganic mercury $\left(B_{H g^{I I}}\right)$ is obtained by integrating Eq. (S18) for the whole horizontal surface of the basin, and for the whole year.

The mass transfer coefficient for the inorganic mercury at the water-sediment interface $\left(M T C_{\text {sed-water }}^{I I}\right.$ (Ciffroy, 2015) is calculated as follows:

$M T C_{\text {sed-water }}^{I I}=\frac{D_{w-i n} \cdot \varphi_{\text {sed }}^{4 / 3}}{\delta_{\text {sed }}^{I I}+\delta_{w} \cdot \varphi_{\text {sed }}^{4 / 3}}$,

where

- $D_{w-i n}$ is the molecular diffusion coefficient for the inorganic mercury $\left[\mathrm{m}^{2} / \mathrm{h}\right]$;

- $\varphi_{\text {sed }}$ is the porosity of the sediment [dimensionless];

- $\delta_{\text {sed }}^{I I}$ is the boundary layer thickness above the sediment for the inorganic mercury $[\mathrm{m}]$;

- $\delta_{w}$ is the boundary layer thickness below sediment $[m]$.

The molecular diffusion coefficient is that reported by Schulz and Zabel (2006), while the porosity of the sediment is calculated using the values of specific weight and humidity reported in the study of ICRAM (2008). The boundary layer thickness below the sediment is obtained by the marine currents velocities at the seawater-sediment interface, according to previous works (Ciffroy, 2015; Sørensen et al., 2001). Finally, the boundary layer thickness above the sediment for the inorganic mercury is calibrated on the basis of benthic mercury fluxes measured close to the seabed during the oceanographic surveys of September 2011 and June 2012 (Salvagio Manta et al., 2016).

Unlike the mass transfer coefficient for the inorganic mercury at the water-sediment interface $\left(M T C_{\text {sed-water }}^{I I}\right)$, the mass transfer coefficient for the inorganic mercury within the sediment is estimated by considering an alternative mechanism for the mercury diffusion in the pore water, in accordance with recent works (Schulz and Zabel, 2006; Ogrinc et al., 2007). Initially we calculate the molecular diffusion coefficient for the inorganic mercury in the pore water of the sediment $\left(D_{\text {sed }}^{\text {in }}\right)$ as follows (Boudreau, 1996; Ogrinc et al., 2007):

$D_{\text {sed }}^{\text {in }}=\varphi_{\text {sed }} \cdot \frac{D_{w-i n}}{\theta^{2}}=\frac{\varphi_{\text {sed }} \cdot D_{w-i n}}{1-\ln \left(\varphi_{\text {sed }}^{2}\right)}$,

where $\theta$ is the tortuosity of the sediment [dimensionless], which is estimated from porosity using the equation by Boudreau (1996).

160 According to Oliveri et al. (2016), we calculate the inorganic mercury concentration in the pore water and the total mercury concentration in the sediment as a function of time, by using the following differential equations:

$$
\begin{gathered}
\frac{d H g_{\text {pore-water }}^{I I}}{d t}=+K_{\text {demeth }} \cdot M e H g_{\text {pore-water }}-K_{\text {meth }} \cdot H g_{\text {pore-water }}^{I I}+\frac{\partial}{\partial x}\left[D_{\text {sed }}^{\text {in }} \cdot \frac{\partial H g_{\text {pore-water }}^{I I}}{\partial x}\right] \\
+\frac{\partial}{\partial y}\left[D_{\text {sed }}^{\text {in }} \cdot \frac{\partial H g_{\text {pore-water }}^{I I}}{\partial y}\right]+\frac{\partial}{\partial z}\left[D_{\text {sed }}^{\text {in }} \cdot \frac{\partial H g_{\text {pore-water }}^{I I}}{\partial z}\right]-\frac{\left(1-f_{M e H g}\right)}{K_{d}^{I I}} \cdot \frac{d H g_{T}^{\text {sed }}}{d t} \\
\frac{d H g_{T}^{\text {sed }}}{d t}=-\alpha \cdot H g_{T}^{\text {sed }} \Rightarrow H g_{T}^{\text {sed }}(t)=H g_{T}^{\text {sed }}(0) \cdot \exp (-\alpha \cdot t), \text { with } \alpha>0,
\end{gathered}
$$

where 
- $K_{\text {demeth }}$ is the rate constant for the de-methylation of methyl-mercury in the pore water of the sediment $[1 / h]$;

- $K_{m e t h}$ is the rate constant for the methylation of inorganic mercury in the pore water of the sediment $[1 / h]$;

- $M e H g_{\text {pore-water }}$ is the methyl-mercury concentration in the pore water of the sediment $\left[\mathrm{\mu g} / \mathrm{m}^{3}\right]$;

- $\alpha$ is the de-adsorption rate (constant) for the total mercury concentration in the sediment $[1 / h]$;

- $f_{M e H g}$ is the fraction of methyl-mercury in the sediment [dimensionless];

- $K_{d}^{I I}$ is the sediment-pore water distribution coefficient for the inorganic mercury $[l / K g]$.

The rate constants of the first equation, except $\alpha$, have been estimated for the Gulf of Trieste by Melaku Canu et al. (2015), while the fraction of methyl-mercury in the sediment has been measured during the oceanographic survey of October 2017. Finally, the de-adsorption rate for the total mercury concentration and the sediment-pore water distribution coefficient for the inorganic mercury have been calibrated on the basis of the mercury concentration measured experimentally in the samples of pore water collected in May 2011 (Oliveri et al., 2016).

\section{S1.2.3 Initial conditions for the total mercury concentration, specific weight and humidity in the sediments. Interpolation methods}

The spatial distribution of total mercury, specific weight and percentage of the humidity of the sediments of the Augusta Bay were estimated within the whole study area in order to simulate mercury flux at the sediment/water interface and between sediment layers. The vertical profiles of these variables were interpolated through Inverse Distance Weighting (IDW) on transects of points of a mesh $18 \times 10$ with $454.6 \mathrm{~m}$ of distance between the nodes, able to cover the entire investigated area. The values corresponding to the nodes at depth $10 \mathrm{~cm}, 30 \mathrm{~cm}, 50 \mathrm{~cm}, 90 \mathrm{~cm}, 110 \mathrm{~cm}, 130 \mathrm{~cm}, 150 \mathrm{~cm}, 170 \mathrm{~cm}$ and $190 \mathrm{~cm}$ were extracted and included as input data in the mathematical model.

\section{S1.3 Dissolved methyl-mercury concentration}

\section{S1.3.1 Boundary conditions at the water-atmosphere interface - Dissolved methyl-mercury concentration}

According to Mason et al. (2012), the methyl-mercury flux at the water-atmosphere interface ( $\mathrm{z}=0)$ is estimated to be $0.5 \%$ of total $H g$ deposition flux ( $\simeq 0.5 \%$ of $H g^{I I}$ deposition flux). Therefore, in our model we set:

$$
\left.\left[D_{z} \frac{\partial M e H g}{\partial z}-v_{z} M e H g\right]\right|_{z=0}=W e t d e p_{M e H g}+\operatorname{Drydep}_{M e H g}=\left.0.005 \cdot\left[D_{z} \frac{\partial H g^{I I}}{\partial z}-v_{z} H g^{I I}\right]\right|_{z=0},
$$

where

- Wetdep $p_{M e H g}$ is the surface wet deposition flux of methyl-mercury $\left[n g \cdot m^{-2} \cdot h^{-1}\right]$;

- Drydep $p_{M e H g}$ is the surface dry deposition flux of contaminated particles $\left[n g \cdot m^{-2} \cdot h^{-1}\right]$; 
The annual atmospheric deposition of the methyl-mercury is calculated by integrating Eq. (S22) for the whole horizontal surface of the basin and for the whole year. The annual total atmospheric mercury deposition (AD) is equal to the sum of the amounts of elemental, inorganic and methyl mercury deposited on the surface of the Augusta basin in one year.

\section{S1.3.2 Boundary conditions at the water-sediment interface - Dissolved methyl-mercury concentration}

195 The methyl-mercury flux at the water-sediment interface $\left(z=z_{b}\right)$ is calculated as a function of time in each position (x,y) of the domain (River Merlin-Expo model, 2015) (Covelli et al., 2008; Ciffroy, 2015):

$$
\left.\left[D_{z} \frac{\partial M e H g}{\partial z}-v_{z} M e H g\right]\right|_{z=z_{b}}=M T C_{\text {sed-water }}^{M M} \cdot\left(M e H g_{p o r e-w a t e r}-\left.M e H g\right|_{z=z_{b}}\right)
$$

where

- $M T C_{\text {sed-water }}^{M M}$ is the mass transfer coefficient for the methyl-mercury at the water-sediment interface $[\mathrm{m} / \mathrm{h}]$, which takes on a different value in each position $(\mathrm{x}, \mathrm{y})$ of the domain;

- $\mathrm{MeHg} g_{\text {pore-water }}$ is the methyl-mercury concentration in the pore water of the shallowest layer of the sediment $\left[\mu \mathrm{g} / \mathrm{m}^{3}\right]$;

- $\left.M e H g\right|_{z=z_{b}}$ is the dissolved methyl-mercury concentration in the deepest layer of seawater $\left[\mu \mathrm{g} / \mathrm{m}^{3}\right]$;

- $z_{b}$ is the depth of the water column $[m]$ in each position $(\mathrm{x}, \mathrm{y})$.

The annual benthic flux of methyl-mercury $\left(B_{\mathrm{MeH}}\right)$ is obtained by integrating Eq. (S23) for the whole horizontal surface of the basin and for the whole year. The annual mercury benthic flux (B) is equal to the sum of the amounts of inorganic mercury and methyl-mercury released from the sediments of the Augusta Bay in one year.

The mass transfer coefficient for the methyl-mercury at the water-sediment interface $\left(M T C_{\text {sed-water }}^{M M}\right)$ (Ciffroy, 2015) is calculated as follows:

$M T C_{\text {sed-water }}^{M M}=\frac{D_{w-o r} \cdot \varphi_{\text {sed }}^{4 / 3}}{\delta_{\text {sed }}^{M M}+\delta_{w} \cdot \varphi_{\text {sed }}^{4 / 3}}$,

210 where

- $D_{w-o r}$ is the molecular diffusion coefficient for the methyl-mercury $\left[m^{2} / h\right]$;

$-\varphi_{\text {sed }}$ is the porosity of the sediment [dimensionless];

- $\delta_{\text {sed }}^{M M}$ is the boundary layer thickness above the sediment for the methyl-mercury $[m]$;

- $\delta_{w}$ is the boundary layer thickness below the sediment $[m]$.

215 Here, the boundary layer thickness above the sediment for the methyl-mercury is calibrated on the basis the methyl-mercury concentration measured close to the seabed during the oceanographic surveys of October 2017.

The molecular diffusion coefficient for methyl-mercury is calculated similarly to that for inorganic mercury (see Eq. (S20) of 
Section 1.2.2).

Then, according to Oliveri et al. (2016), we calculate the methyl-mercury concentration in the pore water and the total mercury concentration in the sediment as a function of time, by considering the molecular diffusion within the sediment, as follows:

$$
\begin{gathered}
\frac{d M e H g_{\text {pore-water }}}{d t}=-K_{\text {demeth }} \cdot M e H g_{\text {pore-water }}+K_{\text {meth }} \cdot H g_{\text {pore-water }}^{I I}+\frac{\partial}{\partial x}\left[D_{\text {sed }}^{\text {or }} \cdot \frac{\partial M e H g_{\text {pore-water }}}{\partial x}\right] \\
+\frac{\partial}{\partial y}\left[D_{\text {sed }}^{\text {or }} \cdot \frac{\partial M e H g_{\text {pore-water }}}{\partial y}\right]+\frac{\partial}{\partial z}\left[D_{\text {sed }}^{\text {or }} \cdot \frac{\partial M e H g_{\text {pore-water }}}{\partial z}\right]-\frac{f_{M e H g}}{K_{d}^{M M}} \cdot \frac{d H g_{T}^{\text {sed }}}{d t} \\
\frac{d H g_{T}^{\text {sed }}}{d t}=-\alpha \cdot H g_{T}^{\text {sed }} \Rightarrow H g_{T}^{\text {sed }}(t)=H g_{T}^{\text {sed }}(0) \cdot \exp (-\alpha \cdot t), \text { with } \alpha>0
\end{gathered}
$$

where

- $K_{\text {demeth }}$ is the rate constant for the de-methylation of methyl-mercury in the pore water of the sediment $[1 / h]$;

- $K_{\text {meth }}$ is the rate constant for the methylation of inorganic mercury in the pore water of the sediment $[1 / h]$;

- $H g_{\text {pore-water }}^{I I}$ is the inorganic mercury concentration in the pore water of the sediment $\left[\mu \mathrm{g} / \mathrm{m}^{3}\right]$;

- $\alpha$ is the de-adsorption rate (constant) for the total mercury concentration in the sediment $[1 / h]$;

- $f_{M e H g}$ is the fraction of the methyl-mercury in the sediment [dimensionless];

- $K_{d}^{M M}$ is the sediment - pore water distribution coefficient for methyl-mercury $[l / K g]$.

Here, the rate constants, the de-adsorption rate and the fraction of the methyl-mercury are the same of Eq. (S21) (see Section 1.2.2), while the sediment-pore water distribution coefficient for the methyl-mercury is fixed equal to the square root of the distribution coefficient for the inorganic mercury, according to Liu et al. (2012).

\section{S2 SPM concentration}

In this work, we reproduced the spatial distribution of SPM and POM concentration at the steady state by interpolating the experimental data observed in recent samplings (October 2017) performed in the site investigated. Specifically, the $S P M$ and $P O M$ values obtained in the sampling stations at the surface and bottom layers were linearly interpolated on the $\mathrm{z}$-direction, in such a way to get different values for each vertical layer. Then, for each batimetry, on the x-y plane, the $S P M$ value of each node of the grid has been determined as the weighted sum of the station values, with weight coefficients set as the inverse square distances of node centroids from the stations.

In general, the used setting is acceptable because the net flux of particles, due to the settling and the resuspension processes, is negligible according to a preliminary analysis performed by IAS-CNR (Oristano).

The experimental SPM and POM concentrations were used to reproduce the spatial distribution of the fraction of suspended particulate matter as organic carbon $\left(f_{o c}\right)$, which was necessary to obtain the sinking fluxes of $\mathrm{Hg}^{I I}$ and $\mathrm{MeHg}$ (Zhang et al., 2014). Afterwards, the $S P M$ concentrations were used to calculate the $\left[H g_{T}\right]$ in seawater (see Section 3.1). 


\section{S2.1 SPM, SPIM and POM concentration}

245 According to Zhang et al. (2014) and Rosati et al. (2018), the suspended particulate matter was defined as follows:

$S P M=S P I M+P O M$,

where

- SPIM is the Suspended Particulate Inorganic Matter concentration $[n g / l]$;

- POM is the Suspended Particulate Organic Matter concentration $[n g / l]$.

250 Specifically, the particulate organic matter (POM) in dissolved-phase and the suspended particulate inorganic matter (SPIM) were given by:

$$
\begin{aligned}
P O M & =f_{\text {org }} \cdot S P M, \\
S P I M & =\left(1-f_{\text {org }}\right) \cdot S P M,
\end{aligned}
$$

where

- $f_{\text {org }}$ is the organic fraction of suspended particulate matter [dimensionless].

Since we assumed that $52 \%$ of organic matter was carbon (Strode et al., 2010), the fraction of suspended particulate matter as organic carbon was calculated by using the following equation:

$f_{\text {oc }}=0.52 \cdot f_{\text {org }}=0.52 \cdot \frac{P O M}{S P M}$

\section{S3 The 3D hydrodynamic model}

260 A three-dimensional, finite element hydrodynamic model, SHYFEM (Umgiesser et al., 2004) was adopted to reproduce the tide and wind induced water circulation, and the sediment transport processes in Augusta Harbour and adjacent coastal area. The model resolves, for each layer, the vertically integrated shallow water equations in their formulation with water levels and transport terms. It was applied with success to reproduce the main hydrodynamics in gulfs, harbours, lagoons and coastal seas (Cucco et al., 2012; Umgiesser et al., 2014; Ferrarin et al., 2014; Cucco et al., 2016a; Farina et al., 2018). The model uses finite elements for horizontal spatial discretizations, z-layers for vertical discretizations and a semi-implicit algorithm for integration in time. It accounts for barotropic, baroclinic and atmospheric pressure gradients as well as wind drag and bottom friction, non-linear advection and vertical turbulent processes. The solved equation system reads as:

$$
\begin{gathered}
\frac{\partial U_{l}}{\partial t}+A d v_{l}^{x}-f V_{l}=g h_{l} \frac{\partial \zeta}{\partial x}-\frac{g h_{l}}{\rho_{0}} \frac{\partial}{\partial x} \int_{-H_{l}}^{\zeta} \rho^{\prime} d z+\frac{h_{l}}{\rho_{0}} \frac{\partial p_{a}}{\partial x}+\frac{1}{\rho_{0}}\left(\tau_{x}^{t o p(l)}-\tau_{x}^{b o t(l)}\right)+A_{H}\left(\frac{\partial^{2} U_{l}}{\partial x^{2}}+\frac{\partial^{2} U_{l}}{\partial y^{2}}\right), \\
\frac{\partial V_{l}}{\partial t}+A d v_{l}^{y}-f U_{l}=g h_{l} \frac{\partial \zeta}{\partial y}-\frac{g h_{l}}{\rho_{0}} \frac{\partial}{\partial y} \int_{-H_{l}}^{\zeta} \rho^{\prime} d z+\frac{h_{l}}{\rho_{0}} \frac{\partial p_{a}}{\partial y}+\frac{1}{\rho_{0}}\left(\tau_{y}^{t o p(l)}-\tau_{y}^{b o t(l)}\right)+A_{H}\left(\frac{\partial^{2} V_{l}}{\partial x^{2}}+\frac{\partial^{2} V_{l}}{\partial y^{2}}\right), \\
\frac{\partial \zeta}{\partial t}+\sum_{l} \frac{\partial U_{l}}{\partial x}+\sum_{l} \frac{\partial V_{l}}{\partial y},
\end{gathered}
$$


where $l$ indicates the vertical layer, $\left(U_{l}, V_{l}\right)$ the horizontal transport components in $x$ - and $y$ - directions for each layer $l$, $A d v_{l}^{x}$ and $A d v_{l}^{y}$ the advective terms for each layer $l, p_{a}$ the atmospheric pressure, $g$ the gravitational constant, $f$ the Coriolis parameter, $\zeta$ the water level, $\rho_{0}$ the standard water density, $\rho^{\prime}$ the water density, $h_{l}$ the layer thickness, $H_{l}$ the depth of the bottom of the layer $l, \tau_{x}^{t o p(l)}$ and $\tau_{x}^{b o t(l)}$ the stress terms in the $x$-direction at the top and bottom of each layer $l, \tau_{y}^{t o p(l)}$ and $\tau_{y}^{b o t(l)}$ the stress terms in the $y$-direction at the top and bottom of each layer $l, A_{h}$ the horizontal eddy viscosity. For the computation of the vertical diffusivities and viscosities, the General Ocean Turbulence Model (GOTM), described in Burchard and Petersen (1999), was used. Wind and bottom friction terms, corresponding to the boundary conditions of the stress terms $\left(\tau_{x}, \tau_{y}\right)$, are defined as:

$$
\begin{aligned}
\tau_{x}^{\text {surface }} & =C_{D} \rho_{a} w_{x} \sqrt{w_{x}^{2}+w_{y}^{2}}, \\
\tau_{x}^{\text {bottom }} & =C_{B} \rho_{0} u_{L} \sqrt{u_{L}^{2}+v_{L}^{2}}, \\
\tau_{y}^{\text {surface }} & =C_{D} \rho_{a} w_{y} \sqrt{w_{x}^{2}+w_{y}^{2}}, \\
\tau_{y}^{\text {bottom }} & =C_{B} \rho_{0} v_{L} \sqrt{u_{L}^{2}+v_{L}^{2}},
\end{aligned}
$$

280 where $C_{D}$ is the wind drag coefficient, $C_{B}$ the bottom friction coefficient, $\rho_{a}$ the air density, $\left(w_{x}, w_{y}\right)$ the wind velocity components and $\left(u_{L}, v_{L}\right)$ the bottom velocity components.

The reader can refer to Umgiesser et al. (2004) for a detailed description of the hydrodynamic model equations and the adopted numerical methods and parameterization.

\section{S3.1 Hydrodynamic model and simulations setup}

The model domain was defined between the $15.05^{\circ} \mathrm{E}$ and $15.55^{\circ} \mathrm{E}$ and between the $36.95^{\circ} \mathrm{N}$ and $37.35^{\circ} \mathrm{N}$, including the Augusta Harbuor, the surrounding coastal areas and part of the Western Ionian Sea.

A finite element mesh composed by 21379 nodes and 40486 triangular elements with a spatial resolution varying between 20 meters for the inner harbour and few $\mathrm{km}$ for the far field was used for the horizontal discretization. The vertical direction was defined by $22 z$-levels with layer depths ranging between $5 \mathrm{~m}$ and $200 \mathrm{~m}$, by following an ad-hoc step distribution. The model temporal integration was set as variable in time and limited to a Courant number equal to 0.5 , with time steps generally around 20 seconds.

The data used to reproduce the model bathymetry were obtained integrating the large-scale GEBCO dataset (http://www.gebco.net) with data obtained from the digitalization of the nautical charts describing the Augusta Harbour and surrounding coastal areas. In Fig.S6, the bathymetry and part of the finite element mesh reproducing the Augusta Bay and surrounding areas are shown.

295 The model was applied to reproduce the tide and wind induced water circulation, and the sediment transport during a ten years period between January 2007 and December 2017.

Baroclinic density gradients were neglected, being the interested coastal area not influenced by intense river inflows. The density vertical distribution was set as homogeneous and the GOTM (Burchard and Petersen, 1999) was used to reproduce the momentum transfer between each layers without any constrain related to the buoyancy variability along the vertical. The use of 
un-stratified model setup is generally acceptable if the interested domain is not affected by estuarine processes (Spydell et al., 2015; Cucco et al., 2016b). Therefore, wind and tide were set as the only external forcings promoting the water circulation in the harbour and surrounding coastal area. A similar approach was followed in several studies aimed at investigating the water circulation in bays, lagoons and harbours of the Mediterranean Sea, typically characterized by an extended shelf area and by the absence of intense fresh water inputs.

The wind data produced by the high-resolution non-hydrostatic meteorological prediction system SKIRON (Kallos and Pytharoulis, 2005) were used as model inputs. In particular, hourly fields of wind speeds and directions, obtained for the whole 10 years period and for the interested area with a spatial resolution of $0.008^{\circ}$, were considered as model surface forcings. In addition, water elevation data were imposed along the model open boundary, corresponding to the open sea mesh border, following a Dirichlet condition. Adopted water level data consisted in hourly time series of tidal elevation. These data were obtained, for the whole considered period, from the global tidal model OTIS (http://volkov.oce.orst.edu/tides/otis.html). Common values of the main model parameters $C_{D}$ and $C_{B}$ (see Eq. (S31)) were imposed (Cucco et al., 2019) and a 10 years simulation run was carried out to reproduce the wind and tide induced water circulation inside the harbour at different vertical levels.

The model results consisted in hourly fields of the horizontal components of the current velocities computed at the surface level, between 0 and $5 \mathrm{~m}$, and at deeper layers, between 5 and $10 \mathrm{~m}, 10$ and $20 \mathrm{~m}$, and 20 and $30 \mathrm{~m}$, for each nodes of the finite element mesh along the whole simulation run. These data were subsequently processed to be used as input data for the biogeochemical model. As first step, a three-hours time averaged velocity field was derived from a time average procedure by using the SHYFEM model output produced at hourly frequency. Afterwards, the dataset of three hourly velocity field was used as input data for the second step of re-processing. In particular, an interpolation procedure based on the Laplacian method was applied to regrid the SHYFEM model outputs (obtained on an unstructured mesh) on the biogeochemical model computational grid. In Fig.S7, a snapshot of the horizontal components of the current velocities, obtained for the four selected vertical layers, are shown along with the points constituting the biogeochemical model computational regular mesh.

The results obtained from the interpolation procedure consist in three hourly sequences of the horizontal components of the current speed. These values, calculated for a period of one year (from January 2011 to December 2011) at each point of the biogeochemical model grid, were used as input data to simulate the transport of the pollutants in the Augusta Bay.

\section{S3.2 Hydrodynamic model validation}

In shallow waters the hydrodynamic is mainly driven and influenced by several elements, including bathymetry, tidal oscillations, wind fields or density gradient. The latter contribution assumes a significant impact only when large freshwater inflow or thermal differences occur in the region (Van Rijn, 2011). In the Augusta bay, due to the seasonal and discontinuous riverine discharges, the contribution of freshwater inputs to spatial density gradients generation is negligible. Furthermore, the homogeneous and shallow bathymetry and the relatively small extent of the bay led to suppose that the spatial variability of the water temperature is not significant and therefore not strongly influencing the water circulation. This hypothesis is confirmed by Lisi et al. (2009), which suggests that the water circulation in the Augusta bay is influenced mainly by tides and wind and the harbour can be investigated as a lagoon (Lisi et al., 2009). In De Marchis et al. (2014) a modelling study of the water circulation 
of the Augusta bay was performed. A high resolution hydrodynamic model was applied to the harbour area and the wind and tide induced three-dimensional water circulation was investigated with success. The absence of available experimental data on water currents or tidal elevation led to compare SHYFEM model results with the numerical results obtained by De Marchis et al. (2014).

In order to make the two numerical applications comparable, SHYFEM was applied to reproduce the wind and tide induced water circulation during the same investigated period and adopting the same atmospheric forcing of De Marchis et al. (2014). Specifically, a graph digitizing software was applied to extract the wind speed components to be used as SHYFEM model forcing whereas the tidal data obtained from OTIS tidal model for the reference period was used as model open boundary conditions.

A simulation run was then performed using the same parameter setup of the previous 10 years simulation run with the exception of the model vertical discretization which was slightly modified setting the first layers depths to $0.5 \mathrm{~m}$. A spin up time of about 2 months was used to reduce the impact of the initial state conditioning and the three-dimensional water circulation was reproduced between the $10^{t h}$ and the $16^{\text {th }}$ of October 2006. In Fig.S8 the model results for the surface (upper panels) and deeper layer water circulation (lower panels) are reported for the same time instants of Fig.10 and 11 of De Marchis et al. (2014) which correspond to the $13^{\text {th }}$ October 2006 at 16:00 and the $14^{\text {th }}$ October 2006 at 15:00. For both the time instants the wind speed is quite low, around $2.5 \mathrm{~m} / \mathrm{s}$ and the wind directions are from Northwest in left panels and from Northeast in the right panels. The computed surface currents (upper panels of Fig.S8) follow the wind directions slightly bending rightward due to the Coriolis force. In the left panel, the surface flow varies between few $\mathrm{cm} / \mathrm{s}$ along the bay perimeter up to around 10 to $12 \mathrm{~cm} / \mathrm{s}$ in correspondence of the eastern mouth. In the right panel the surface current speed is quite homogeneous within the bay with values around $10 \mathrm{~cm} / \mathrm{s}$ and peaks of $13 \mathrm{~cm} / \mathrm{s}$ computed in the south central part of the harbour. The obtained flow patterns are quite similar to the ones reported in De Marchis et al. (2014), which, in the first case, reported a south-eastward surface flow with current speeds increasing toward the eastern bay inlet up to $12-13 \mathrm{~cm} / \mathrm{s}$ (see panel C of Fig.10 in De Marchis et al. (2014)) and, in the second case, a south-westward surface flow mainly homogeneous and slightly increasing up to 13-14 $\mathrm{cm} / \mathrm{s}$ in the southern part of the bay (see panel C of Fig.11 in De Marchis et al. (2014)). The same analogy is found for deeper layer flow fields computed for both the time instants, see lower panels of Fig.S8. In particular, in the left bottom panel, the sub-surface flow is varying in intensities, with peak speeds up to $3-4 \mathrm{~cm} / \mathrm{s}$ in the central part of the bay, and in directions, from northward to north-eastward. In the right bottom panel, the current field is mainly directed north-westward and the speed is varying similarly to previous case. Comparing the obtained results with ones from previous application (see panels $\mathrm{F}$ of Fig.10 and 11 in De Marchis et al. (2014)), even the deeper layers current flows are similarly reproduced by the two numerical applications.

This analysis compensates the absence of experimental data to be used as reference for quantitative model results evaluation. The small differences between the flow patterns obtained from the two applications can arise from many aspects including the different adopted numerical models and methods and the different vertical discretizations of the model domain. Furthermore, the analysed time period, early October, allow to strength the hypothesis of Lisi et al. (2009) about the lagoon-type water circulation in the Augusta bay. In fact, in De Marchis et al. (2014), not only the baroclinic contribution was neglected but also 
the thermal stratification effects on the water circulation was not considered. Therefore, the success in modelling the bay hydrodynamic during early October and with relatively low wind speeds, when, in the southern Mediterranean areas the summer stratification still exist, indicates that, for this study case, the use of an un-stratified model approach can be acceptable.

\section{S4 The advection-diffusion-reaction model for the picoeukaryotes community}

Our study includes the analysis of the abundance of picoeukaryotes community (i.e. phytoplanktonic eukaryotes with size less than $3 \mu \mathrm{m}$ ), which represents the set of most representative populations of the Augusta Bay. In particular, we investigate the dynamics of the primary production of phytoplankton biomass by using an advection-diffusion-reaction model (Dutkiewicz et al., 2009; Morozov et al., 2010; Valenti et al., 2012; Denaro et al., 2013a, c, b; Valenti et al., 2015, 2016a, b, c, 2017), in which the effects of the growth limiting factors, i.e. light intensity and nutrient concentration, are taken into account. By solving the equations of the model, we get the steady spatial distribution of picoeukaryotes abundance, expressed in cells per unit volume and indicated by $b(x, y, z, t)$. Moreover, the spatial distributions of the phosphate concentration $R(x, y, z, t)$ and light intensity $I(x, y, z, t)$ are obtained.

The dynamics of the picoeukaryotes abundance is modeled by considering three processes (Valenti et al., 2012; Denaro et al., 2013a, c, b; Valenti et al., 2015, 2016a, b, c, 2017): i) net growth (reaction term); ii) passive movement (advection terms); iii) movement due to turbulence (diffusion terms).

The reaction term describes the nonlinear interactions between the net growth of picoeukaryotes abundance and the two limiting resources, i.e. light intensity and nutrient concentration. In particular, the net phytoplankton growth rate $(G(x, y, z, t))$ represents the balance between the gross production rate per capita and the mortality (Valenti et al., 2012; Denaro et al., 2013a, c, b; Valenti et al., 2015, 2016a, 2017). The former is given by $\min \left\{f_{I}(I), f_{R}(R)\right\}$, where $f_{I}(I)$ and $f_{R}(R)$ are obtained by the Michaelis-Menten formulas for light intensity and phosphate concentration (Valenti et al., 2012; Denaro et al., 2013a, c, b; Valenti et al., 2015, 2016a, 2017). The latter is described by the specific loss rate $(m)$, in which we consider three processes: respiration, death, and grazing.

The advection terms allow to describe the effects on the spatial distribution of picoeukaryotes abundance induced both by the sinking velocity $\left(w_{z}\right)$ along the $z$-direction, typical of the planktonic population investigated, and by the velocity field of marine currents reproduced by the SHYFEM model. The diffusion terms reproduce the effects of the turbulence on the spatial distribution of the picoeukaryotes community through the horizontal $\left(D_{x}=D_{y}\right)$ and the vertical $\left(D_{v}\right)$ turbulent diffusivities, whose values are the same used previously for mercury concentrations.

The equation for the dynamics of phosphate concentration $R(x, y, z, t)$ includes two reaction terms, which describe two different processes: i) the phosphate increase due to the recycling of the dead phytoplankton; ii) the phosphate decrease due to the uptake of the picoeukaryotes community. Moreover, also in this case, the effects of the local transport and turbulence, responsible for the mixing of nutrients in the 3D domain, are considered by inserting in the differential equation for the phosphate concentration three advection terms and three diffusion terms, respectively.

Finally, the light intensity $I(z, t)$ is assumed to decrease exponentially with the depth $z$, according to the Lambert-Beer's 
law (Valenti et al., 2012; Denaro et al., 2013a, c, b; Valenti et al., 2015, 2016a, 2017), and to vary as a function of time $t$ due to the seasonal oscillations of the incident light intensity, $I_{i n}(t)$.

Therefore, the model for picoeukaryotes community is defined by the following equations:

$$
\begin{aligned}
\frac{\partial b}{\partial t}= & +\frac{\partial}{\partial x}\left[D_{x} \frac{\partial b}{\partial x}\right]-\frac{\partial}{\partial x}\left(v_{x} b\right)+\frac{\partial}{\partial y}\left[D_{y} \frac{\partial b}{\partial y}\right]-\frac{\partial}{\partial y}\left(v_{y} b\right)+\frac{\partial}{\partial z}\left[D_{z} \frac{\partial b}{\partial z}\right]-\frac{\partial}{\partial z}\left(v_{z} b\right)-\frac{\partial}{\partial z}\left(w_{z} b\right) \\
& +b \cdot \min \left(f_{I}(I), f_{R}(R)\right)-m b \\
\frac{\partial R}{\partial t}= & +\frac{\partial}{\partial x}\left[D_{x} \frac{\partial R}{\partial x}\right]-\frac{\partial}{\partial x}\left(v_{x} R\right)+\frac{\partial}{\partial y}\left[D_{y} \frac{\partial R}{\partial y}\right]-\frac{\partial}{\partial y}\left(v_{y} R\right)+\frac{\partial}{\partial z}\left[D_{z} \frac{\partial R}{\partial z}\right]-\frac{\partial}{\partial z}\left(v_{z} R\right)+\sum_{i} \varepsilon \cdot m \cdot \frac{b}{Y} \\
& -\frac{b}{Y} \cdot \min \left(f_{I}(I), f_{R}(R)\right),
\end{aligned}
$$

$I(z, t)=I_{\text {in }}(t) \exp \left\{-\int_{0}^{z}\left[a_{b g}+a \cdot c h l a\right] d Z\right\}$.

410 Here, $m$ and $w_{z}$ are the mortality and the sinking velocity of eukaryotes population, respectively; $\varepsilon$ is the nutrient recycling coefficient for the picoeukaryotes community; $1 / Y$ is the nutrient cell content of picoeukaryotes; $a_{b g}$ is the background turbidity; $a$ is the average absorption coefficient for the picoeukaryotes community; chl $a$ is the chlorophyll- $a$ concentration corresponding to the abundance of picoeukaryotes.

The half-saturation constants for growth of picoeukaryotes, used in the the Michaelis-Menten formulas, depend on the environmental conditions of investigated site. Since the chlorophyll-a concentrations, measured in the Augusta Bay, are those typical of oligotrophic waters of the Mediterranean Sea, the half-saturation constants are set equal to values previously obtained in the Southern Sicily by Valenti et al. (2017) adopting an accurate calibration procedure. All other parameters are set in accordance with the methods described in previous works (Hickman et al., 2010; Raven et al., 2005; Veldhuis et al., 2005; Timmermans et al., 2005), while the temporal behaviour of incident light intensity, $I_{i n}(t)$, is obtained for the Augusta Bay by using the remote sensing data. Finally, the chlorophyll-a concentration, chl $a$, is calculated by the theoretical results for the picoeukaryotes abundance by using the conversion curve obtained by Brunet et al. (2007).

The NP model is completed by a set of equations, which describe the nutrient and phytoplankton fluxes at the boundaries of Augusta Bay. Here, we set the following conditions for the picoeukaryotes abundance and the phosphate concentration: no biomass can enter or leave the area investigated except through the inlets; no nutrient flux is present through the water surface; the phosphate concentration at the deepest layer of the water column is fixed equal to the value measured previously close to Augusta Bay; no nutrient flux is present through the lateral surfaces except at the inlets; the picoeukaryotes abundance and the phosphate concentration are set constant out of the Augusta Bay (Mediterranean Sea); the lateral fluxes for picoeukaryotes abundance and phosphate concentration at the inlets depend on the behaviour of horizontal velocities. The boundary conditions for the picoeukaryotes abundance and the phosphate concentration are defined by the following equations: 


$$
\left[D_{x} \frac{\partial b}{\partial x}-v_{x} b\right]=\left[D_{y} \frac{\partial b}{\partial y}-v_{y} b\right]=0, \quad b\left(x_{\text {inlet }}, y_{\text {inlet }}, z\right)=b_{\text {ext }},
$$

$$
\left.\frac{\partial R}{\partial z}\right|_{z=0}=0, \quad R\left(x, y, z_{b}\right)=R_{i n}\left(x, y, z_{b}\right),
$$

$$
\left[D_{x} \frac{\partial R}{\partial x}-v_{x} R\right]=\left[D_{y} \frac{\partial R}{\partial y}-v_{y} R\right]=0, \quad R\left(x_{\text {inlet }}, y_{\text {inlet }}, z\right)=R_{\text {ext }},
$$

where $z_{b}$ is the depth of the water column in each position (x,y); $b_{e x t}$ is the average picoeukaryotes abundance in the Mediterranean Sea; $R_{i n}\left(x, y, z_{b}\right)$ is the phosphate concentration kept constant at the deepest layer of the water column; $R_{e x t}$ is the average phosphate concentration in the Mediterranean Sea.

Eqs. (S32)-(S38) describe the three-dimensional advection-diffusion-reaction model used to reproduce the spatio-temporal behaviour of the picoeukaryotes abundance, the phosphate concentration and the light intensity in the seawater compartment of the Augusta Bay. The theoretical results obtained by this model are used to calculate the sinking fluxes of the $S P M$-bound mercury and the loads of dissolved mercury released by POM.

\section{S5 The Phytoplankton MERLIN-Expo model for the mercury contents in picoeukaryotes}

The dynamics of the mercury content in picoeukaryotes is analyzed in the Augusta Bay by using the Phytoplankton MERLINExpo model (Radomyski and Ciffroy, 2015). Specifically, we investigate the behaviour of the most abundant two mercury species within the phytoplankton cells, i.e. inorganic mercury and methyl-mercury. By solving the equations of the model, we obtain the dynamics of the amount of inorganic mercury and methyl-mercury present in each picoeukaryote cell, indicated by $\mathrm{PHg}^{I I}(x, y, z, t)$ and $\mathrm{PMeHg}(x, y, z, t)$, respectively.

The dynamics of the content of inorganic mercury and methyl-mercury in each picoeukaryote cell is modeled by considering three processes (Radomyski and Ciffroy, 2015): i) mercury absorption through the cell wall; ii) mercury elimination (excretion) through the cell wall; iii) mercury elimination via dilution. The first process is described by the uptake rate constant for the mercury, which is obtained by the water layer diffusion resistance, the lipid permeation resistance and the mercury concentration in the seawater. The second process is described by the elimination rate constant for the mercury, which depends on the water layer diffusion resistance, the lipid permeation resistance and the water-dissolved organic carbon partition coefficient. The third process is described by the growth rate constant for picoeukaryotes, which is obtained by the phytoplankton growth rate and the phytoplankton weight.

Thus, the Phytoplankton Merlin-Expo model (Radomyski and Ciffroy, 2015) for the two mercury species embedded at the picoeukaryotes cells is defined by the following equations:

$460 \frac{d P H g^{I I}}{d t}=W_{p h y} \cdot k_{p h y, u p, \text { inor }} \cdot H g^{I I}-P H g^{I I} \cdot\left(k_{p h y, \text { exc }, \text { inor }}+k_{p h y, g r o}\right)$, 
$\frac{d P M e H g}{d t}=W_{p h y} \cdot k_{p h y, u p, m e t h} \cdot M e H g-P M e H g \cdot\left(k_{p h y, e x c, m e t h}+k_{p h y, g r o}\right)$,

where $W_{p h y}$ is the phytoplankton cell weight, $k_{p h y, u p, i n o r}$ is the inorganic mercury uptake rate constant, $k_{p h y, u p, m e t h}$ is the methyl-mercury uptake rate constant, $k_{p h y, e x c, i n o r}$ is the elimination rate constant for the inorganic mercury, $k_{p h y, e x c, m e t h}$ is the elimination rate constant for the methyl-mercury; $k_{p h y, g r o}$ is the growth rate constant. According to the Phytoplankton Merlin-Expo model (Radomyski and Ciffroy, 2015), the rates of Eqs. (S39)-(S40) are calculated as follows:

$k_{\text {phy }, \text { up }, \text { inor }}=\frac{W_{\text {phy }}^{-k}}{\rho_{\text {water }}+\rho_{\text {lipid }} \cdot\left(H g^{I I}\right)^{b_{\text {lipid }}}}$,

$k_{\text {phy }, \text { up }, \text { meth }}=\frac{W_{\text {phy }}^{-k}}{\rho_{\text {water }}+\rho_{\text {lipid }} \cdot(M e H g)^{b_{\text {lipid }}}}$,

470

$k_{\text {phy }, \text { exc }, \text { inor }}=\frac{W_{\text {phy }}^{-k}}{\rho_{\text {water }}+\rho_{\text {lipid }}} \cdot \frac{1}{p_{\text {carbonphy }} \cdot 10^{\log _{10} K_{d}^{I I}}}$,

$k_{\text {phy }, \text { exc }, \text { meth }}=\frac{W_{\text {phy }}^{-k}}{\rho_{\text {water }}+\rho_{\text {lipid }}} \cdot \frac{1}{p_{\text {carbonphy }} \cdot 10^{\log _{10} K_{d}^{M M}}}$,

$475 k_{\text {phy,gro }}=a_{\text {growth }} \cdot V_{\text {cell }}^{-b_{\text {growth }}}$,

where $W_{p h y}$ and $V_{\text {cell }}$ are the phytoplankton weight and the phytoplankton cell volume of the picoeukaryotes, respectively; $k$ is the allometric rate exponent of the phytoplankton; $\rho_{\text {lipid }}$ and $\rho_{\text {water }}$ are the lipid layer permeation resistance and the water layer diffusion resistance for the uptake of chemicals from water, respectively; $b_{\text {lipid }}$ is the lipid permeation resistance exponent; $\mathrm{Hg}^{I I}$ and $\mathrm{MeHg}$ are the inorganic mercury concentration and the methyl-mercury concentration in the seawater, respectively; $p_{\text {carbonphy }}$ is the organic carbon fraction of phytoplankton; $\log _{10} K_{d}^{I I}$ and $\log _{10} K_{d}^{M M}$ are the water-dissolved organic carbon partition coefficients for the inorganic mercury and the methyl-mercury, respectively; $a_{\text {growth }}$ and $b_{\text {growt }}$ are the intercept and the slope of the phytoplankton growth rate, respectively. The picoeukaryote weight, $W_{p h y}$, and the phytoplankton cell volume, $V_{\text {cell }}$, are estimated by using the experimental findings reported in previous works (Radomyski and Ciffroy, 2015; Pickhardt and Fischer, 2007; Strickland, 1960). The mercury concentrations, $\mathrm{Hg}^{I I}$ and $\mathrm{MeHg}$, in the seawater are obtained by the advection-diffusion-reaction model (see section 1). All other parameters are set at the same values given in "The Phytoplankton Merlin-Expo model" (Radomyski and Ciffroy, 2015; Hendricks, 2007; Hauck et al., 2011; Allison and Allison, 2005).

As initial conditions, we fix that the mercury contents in each picoeukaryote cell depend on both the dissolved mercury concentrations in marine environment and the volume concentration factors estimated for specific chemicals (inorganic mercury 
and methyl-mercury) and phytoplankton species (picoeukaryotes) (Pickhardt and Fischer, 2007). In particular, the inorganic 490 mercury content and the methyl-mercury content at the initial time $(t=0)$ are given by:

$P H g^{I I}(0)=W_{p h y} \cdot V C F^{I I} \cdot H g^{I I}(0), \quad P M e H g(0)=W_{p h y} \cdot V C F^{M M} \cdot M e H g(0)$

where $V C F^{I I}$ and $V C F^{M M}$ are the volume concentration factors for the inorganic mercury and the methyl-mercury, respectively, in picoeukaryotes; $\mathrm{Hg}^{I I}(0)$ and $\mathrm{MeHg}(0)$ are the inorganic mercury concentration and the methyl-mercury concentration at the initial time $t=0$.

495 Eqs. (S39)-(S45) constitute the Phytoplankton MERLIN-Expo model used to reproduce the dynamics of the mercury contents within the picoeukaryotes cells, which populate the Augusta Bay. The theoretical results obtained by this model are used to calculate the loads of dissolved mercury released by the particulate organic matter. 


\section{References}

Allison, J. D. and Allison, T. L.: Partition coefficients for metals in surface water, soil, and waste, U.S. Environmental Protection Agency, Washington, DC, 2005.

Bagnato, E., Sprovieri, M., Barra, M., Bitetto, M., Bonsignore, M., Calabrese, S., Di Stefano, V., Oliveri, E., Parello, F., and Mazzola, S.: The sea-air exchange of mercury $(\mathrm{Hg})$ in the marine boundary layer of the Augusta basin (southern Italy): Concentrations and evasion flux, Chemosphere, 93, 2024-2032, https://doi.org/10.1016/j.chemosphere.2013.07.025, 2013.

Baines, S. B., Pace, M. L., and Karl, D. M.: Why does the relationship between sinking flux and planktonic primary production differ between lakes and oceans?, Limnol. Oceanogr., 39(2), 213-226, https://doi.org/10.4319/lo.1994.39.2.0213, 1994.

Batrakova, N., Travnikov, O., and Rozovskaya, O.: Chemical and physical transformations of mercury in the ocean: a review, Ocean Sci., 10, 1047-1063, https://doi.org/https://doi.org/10.5194/os-10-1047-2014, 2014.

Boudreau, B. P.: The diffusive tortuosity of fine-grained unlithified sediments, Geochim. Cosmochim. Acta, 60, 3139-3142, https://doi.org/https://doi.org/10.1016/0016-7037(96)00158-5, 1996.

Burchard, H. and Petersen, O.: Models of turbulence in the marine environment. A comparative study of two-equation turbulence models, J. Mar. Syst., 21(1-4), 23-53, https://doi.org/10.1016/S0924-7963(99)00004-4, 1999.

Ciffroy, P.: The River MERLIN-Expo model, Fun Project 4 - Seventh Framework Programme, 2015.

Cossa, D. and Coquery, M.: The Handbook of Environmental Chemistry, Vol. 5, Part K (2005): 177-208. The Mediterranean Mercury Anomaly, a Geochemical or a Biologocal Issue, Springer-Verlag Berlin Heidelberg, 2005.

515 Covelli, S., Faganeli, J., De Vittor, C., Predonzani, S., Acquavita, A., and Horvat, M.: Benthic fluxes of mercury species in a lagoon environment (Grado Lagoon, Northern Adriatic Sea, Italy), Appl. Geochem., 23, 529-546, https://doi.org/10.1016/j.apgeochem.2007.12.011, 2008.

Cucco, A., Sinerchia, M., Lefrançois, C., Magni, P., Ghezzo, M., Umgiesser, G., Perilli, A., and Domenici, P.: A metabolic scope based model of fish response to environmental changes, Ecol. Model., 237-238, 132-141, https://doi.org/10.1016/j.ecolmodel.2012.04.019, 2012.

Cucco, A., Quattrocchi, G., Olita, A., Fazioli, L., Ribotti, A., Sinerchia, M., Tedesco, C., and Sorgente, R.: Hydrodynamic modeling of coastal seas: the role of tidal dynamics in the Messina Strait, Western Mediterranean Sea, Nat. Hazard Earth Sys., 16, 1553-1569, https://doi.org/10.5194/nhess-16-1553-2016, 2016a.

Cucco, A., Quattrocchi, G., Satta, A., Antognarelli, F., De Biasio, F., Cadau, E., Umgiesser, G., and Zecchetto, S.: Predictability of wind-induced sea surface transport in coastal areas, J. Geophys. Res. Oceans, 121(8), 5847-5871, https://doi.org/https://doi.org/10.1002/2016JC011643, 2016b.

Cucco, A., Quattrocchi, G., and Zecchetto, S.: The role of temporal resolution in modeling the wind induced sea surface transport in coastal seas, J. Mar. Syst., 193, 46-58, https://doi.org/https://doi.org/10.1016/j.jmarsys.2019.01.004, 2019.

Denaro, G., Valenti, D., La Cognata, A., Spagnolo, B., Bonanno, A., Basilone, G., Mazzola, S., Zgozi, S., Aronica, S., and Brunet, C.: Spatiotemporal behaviour of the deep chlorophyll maximum in Mediterranean Sea: Development of a stochastic model for picophytoplankton dynamics, Ecol. Complex., 13, 21-34, https://doi.org/10.1016/j.ecocom.2012.10.002, 2013a.

Denaro, G., Valenti, D., Spagnolo, B., Basilone, G., Mazzola, S., Zgozi, S., Aronica, S., and Bonanno, A.: Dynamics of two picophytoplankton groups in Mediterranean Sea: Analysis of the Deep Chlorophyll Maximum by a stochastic advection-reaction-diffusion model, PLoS ONE, 8(6), e66 765, https://doi.org/10.1371/journal.pone.0066765, $2013 \mathrm{~b}$. 
Denaro, G., Valenti, D., Spagnolo, B., Bonanno, A., Basilone, G., Mazzola, S., Zgozi, S., and Aronica, S.: Stochastic dynamics of two picophytoplankton populations in a real marine ecosystem, Acta Phys. Pol. B, 44, 977-990, https://doi.org/10.5506/APhysPolB.44.977, $2013 \mathrm{c}$.

Denman, K. L. and Gargett, A. E.: Time and space scales of vertical mixing and advection of phytoplankton in the upper ocean, Limnol. Oceanogr., 28, 801-815, https://doi.org/https://doi.org/10.4319/lo.1983.28.5.0801, 1983.

D'Ortenzio, F.: Space and time occurrence of algal blooms in the Mediterranean: their significance for the trophic regime of the basin, PhD Thesis, Open University of London, UK, 2003.

Dutkiewicz, S., Follows, M. J., and Bragg, J. G.: Modeling the coupling of ocean ecology and biogeochemistry., Global Biogeochem. Cy., p. GB4017, https://doi.org/https://doi.org/10.1029/2008GB003405, 2009.

Farina, S., Quattrocchi, G., Guala, I., and Cucco, A.: Hydrodynamic patterns favouring sea urchin recruitment in coastal areas: A Mediterranean study case, Mar. Environ. Res., 139, 182-192, https://doi.org/10.1016/j.marenvres.2018.05.013, 2018.

Ferrarin, C., Umgiesser, G., Cucco, A., Hsu, T. W., Roland, A., and Amos, C. L.: Development and validation of a finite element morphological model for shallow water basins, Coast. Eng., 55, 716-731, https://doi.org/10.1016/j.coastaleng.2008.02.016, 2008.

Ferrarin, C., Bajo, M., Bellafiore, D., Cucco, A., De Pascalis, F., and Ghezzo, M.: Toward homogenization of Mediterranean lagoons and their loss of hydrodiversity, Geophys. Res. Lett., 41(16), 5935-5941, https://doi.org/https://doi.org/10.1002/2014GL060843, 2014.

Han, S., Lehman, R. D., Choe, K. Y., and Gill, A.: Chemical and physical speciation of mercury in Offatts Bayou: A seasonally anoxic bayou in Galveston Bay, Limnol. Oceanogr., 52(4), 1380-1392, https://doi.org/https://doi.org/10.4319/lo.2007.52.4.1380, 2007.

Hauck, A. J., Hendricks, H. W. M., Huijbregts, M. A. J., Ragas, A. M. J., Van der Meent, D., and Hendricks, A. J.: Parameter uncertainty in modeling bioaccumulation factors of fish, Environ. Toxicol. Chem., 30(2), 403-412, https://doi.org/10.1002/etc.393, 2011.

Hendricks, A. J.: The power of size: A meta-analysis reveals consistency of allometric regressions, Ecol. Model., 205, 196-208, https://doi.org/10.1016/j.ecolmodel.2007.02.029, 2007.

Hickman, A., Dutkiewicz, S., Williams, R., and Follows, M.: Modelling the effects of chromatic adaptation on phytoplankton community structure in the oligotrophic ocean, Mar. Ecol. Prog. Ser., 406, 1-17, 2010.

Hines, M. E., Potrait, E. N., Covelli, S., Faganeli, J., Emili, A., Zizek, E., and Horvat, M.: Mercury methylation and demethylation in Hg-contaminated lagoon sediments (Marano and Grado Lagoon, Italy), Estuar. Coast. Shelf Sci., 113, 85-95, https://doi.org/10.1016/j.ecss.2011.12.021, 2012.

ICRAM: Progetto preliminare di bonifica dei fondali della rada di Augusta nel sito di interesse nazionale di Priolo e Elaborazione definitiva, BoI-Pr-SI-PR-Rada di Augusta-03.22, 2008.

Kallos, G. and Pytharoulis, I.: Short-term predictions (weather forecasting purposes), Encyclopedia of Hydrological Sciences, edited by M. G. Anderson, pp. 2791-2811, John Wiley, London, U.K., 2005.

Katz, E. J., Bruce, J. G., and Petrie, B. D.: Salt and mass flux in the Atlantic Equatorial Undercurrent, Deep-Sea Res., 26, 139-160, 1979.

Lisi, I., Taramelli, A., Di Risio, M., Cappucci, S., and Gabellini, M.: Flushing efficiency of Augusta harbour (Italy), J. Coast. Res., 56, 841-845, 2009.

Liu, G., Cai, J., and O’Driscoll, N.: Environmental Chemistry and Toxycology of Mercury, John Wiley and Sons, Inc., Hoboken, New Jersey, 2012.

Massel, S. R.: Fluid Mechanics for Marine Ecologists, Springer-Verlag, Berlin Heidelberg, 1999. 
Melaku Canu, D., Rosati, G., Solidoro, C., Heimbürger, L., and Acquavita, A.: A comprehensive assessment of the mercury budget in the Marano-Grado Lagoon (Adriatic Sea) using a combined observational modeling approach, Mar. Chem., 177, 742-752, https://doi.org/10.1016/j.marchem.2015.10.013, 2015.

Monperrus, M., Tessier, E., Amouroux, D., Leynaert, A., Huonnic, P., and Donard, O. F. X.: Mercury methylation, demethylation and reduction rates in coastal and marine surface waters of the Mediterranean Sea, Mar. Chem., 107, 49-63, https://doi.org/10.1016/j.marchem.2007.01.018, 2007a.

Monperrus, M., Tessier, E., Point, D., Vidimova, K., Amouroux, D., Guyoneaud, R., Leynaert, A., Grall, J., Chauvaud, L., Thouzeau, G., and Donard, O. F. X.: The biogeochemistry of mercury at the sediment-water interface in the Thau Lagoon. 2. Evaluation of mercury methylation potential in both surface sediment and the column, Estuar. Coast. Shelf Sci., 72, 485-486, https://doi.org/https://doi.org/10.1016/j.ecss.2006.11.014, 2007b.

Morozov, A., Arashkevich, E., Nikishina, A., and Solovyev, K.: Nutrient-rich plankton communities stabilized via predator-prey interactions: revisiting the role of vertical heterogeneity, Math. Med. Biol., 28(2), 185-215, https://doi.org/10.1093/imammb/dqq010, 2010.

Neumeier, U., Ferrarin, C., Amos, C. L., Umgiesser, G., and Li, M. Z.: Sedtrans05: An improved sediment-transport model for continental shelves and coastal waters with a new algorithm for cohesive sediments, Comput. Geosci., 34, 1223-1242, https://doi.org/10.1016/j.cageo.2008.02.007, 2008.

Ogrinc, N., Monperrus, M., Kotnik, J., Fajon, V., Vidimova, K., Amouroux, D., Kocman, D., Tessier, E., Zizek, S., and Horvat, M.: Distribution of mercury and methylmercury in deep-sea surficial sediments of the Mediterranean Sea, Mar. Chem., 107, 31-48, https://doi.org/https://doi.org/10.1016/j.marchem.2007.01.019, 2007.

Oliveri, E., Manta, D. S., Bonsignore, M., Cappello, S., Tranchida, G., Bagnato, E., Sabatino, N., Santisi, S., and Sprovieri, M.: Mobility of mercury in contaminated marine sediments: Biogeochemical pathways, Mar. Chem., 186, 1-10, https://doi.org/10.1016/j.marchem.2016.07.002, 2016.

Pacanowski, R. and Philander, S. G. H.: Parameterization of Vertical Mixing in Numerical Models of Tropical Oceans, J. Phys. Oceanogr., 11, 1443-1451, https://doi.org/10.1175/1520-0485(1981)011<1443:POVMIN>2.0.CO;2, 1981.

Peters, H., Gregg, M. C., and Toole, J. M.: On the Parameterization of Equatorial Turbulence, J. Geophys. Res., 93, 1199-1218, https://doi.org/https://doi.org/10.1029/JC093iC02p01199, 1988.

595 Pickhardt, P. C. and Fischer, N. S.: Accumulation of Inorganic and Methylmercury by Freshwater Phytoplankton in Two Contrasting Water Bodies, Environ. Sci. Technol., 41, 125-131, https://doi.org/10.1021/es060966w, 2007.

Qureshi, A., O’Driscoll, N. J., MacLeod, M., Neuhold, Y. M., and Hungerbuhler, K.: Photoreactions of mercury in surface ocean water: gross reaction kinetics and possible pathways, Environ. Sci. Technol., 44, 644-649, https://doi.org/10.1021/es9012728, 2010.

Radomyski, A. and Ciffroy, P.: The Phytoplankton MERLIN-Expo model, Fun Project 4 - Seventh Framework Programme, 2015.

Rajar, R., Cetina, M., Horvat, M., and Zagar, D.: Mass balance of mercury in the Mediterranean Sea, Mar. Chem., 107, 89-102, https://doi.org/https://doi.org/10.1016/j.marchem.2006.10.001, 2007.

Raven, J. A., Finkel, Z. V., and Irwin, A. J.: Picophytoplankton: bottom-up an top-down controls on ecology and evolution, J. Geophys. Res., $55,209-215,2005$.

Salvagio Manta, D., Bonsignore, M., Oliveri, E., Barra, M., Tranchida, G., Giaramita, L., Mazzola, S., and Sprovieri, M.: Fluxes and the mass balance of mercury in Augusta Bay (Sicily, southern Italy), Estuar. Coast. Shelf Sci., 181, 134-143, https://doi.org/10.1016/j.ecss.2016.08.013, 2016.

Schulz, H. D. and Zabel, M.: Marine Geochemistry, Springer - Verlag Berlin Heidelberg, 2006. 
Soerensen, A. L., Sunderland, E. M., Holmes, C. D., Jacob, D. J., Yantosca, R. M., Skov, H., Christensen, J. H., Strode, S. A., and Mason, R. P.: An improved global model for air-sea exchange of mercury: High concentrations over the north Atlantic, Environ. Sci. Technol., 44, 8574-8580, https://doi.org/10.1021/es102032g, 2010.

Sørensen, P. B., Fauser, P., Carlsen, L., and Vikelsøe, J.: Theoretical evaluation of the sediment/water exchange description in generic compartment models (SimpleBox), NERI Technical Report No.360, 2001.

Spydell, M. S., Feddersen, F., Olabarrieta, M., Chen, J., Guza, R. T., Raubenheimer, B., and Elgar, S.: Observed and modeled drifters at a tidal inlet, J. Geophys. Res. Oceans, 120, 4825-4844, https://doi.org/10.1002/2014JC010541, 2015.

615 Strickland, J. D. H.: Measuring the Production of Marine Phytoplankton, Fisheries Research Board of Canada (Bulletin), 1960.

Strode, S., Jaeglè, L., and Emerson, S.: Vertical transport of anthropogenic mercury in the ocean, Global Biogeochem. Cy., 24, GB4014, https://doi.org/https://doi.org/10.1029/2009GB003728, 2010.

Strode, S. A., Jaegle, L., Selin, N., Jacob, D. J., Park, R., Yantosca, R. M., Mason, R. P., and Slemr, F.: Air-sea exchange in the global mercury cycle, Global Biogeochem. Cy., 21, GB1017, https://doi.org/https://doi.org/10.1029/2006GB002766, 2007.

Sunderland, E. M., Gobas, F. A. P. C., Branfireum, B. A., and Heyes, A.: Environmental controls on the speciation and distribtuion of mercury in coastal sediments, Mar. Chem., 102, 111-123, https://doi.org/10.1016/j.marchem.2005.09.019, 2006.

Thi, N. N. P., Huisman, J., and Sommeijer, B. P.: Simulation of three-dimensional phytoplankton dynamics: competition in light-limited environments, J. Comput. Appl. Math., 174, 57-77, https://doi.org/10.1016/j.cam.2004.03.023, 2005.

Timmermans, K. R., van der Wagt, B., Veldhuis, M. J. W., Maatman, A., and de Baar, H. J. W.: Physiological responses of three species of marine pico-phytoplankton to ammonium, phospahte, iron and light limitation, J. Sea Res., 53, 109-120, 2005.

Tveito, A. and Winther, R.: Introduction to Partial Differential Equations: A Computational Approach, Springer-Verlag, New York, 1998.

Umgiesser, G.: SHYFEM. Finite Element Model for Coastal Seas. User Manual, The SHYFEM Group, Georg Umgiesser, ISMAR-CNR, Venezia, Italy, 2009.

Umgiesser, G., Canu, D. M., Cucco, A., and Solidoro, C.: A finite element model for the Venice Lagoon. Development, set up, calibration and validation, J. Mar. Syst., 51, 123-145, https://doi.org/10.1016/j.jmarsys.2004.05.009, 2004.

Umgiesser, G., Ferrarin, C., Cucco, A., De Pascalis, F., Bellafiore, D., Ghezzo, M., and Bajo, M.: Comparative hydrodynamics of 10 Mediterranean lagoons by means of numerical modeling, J. Geophys. Res. Oceans, 119(4), 2212-2226, https://doi.org/https://doi.org/10.1002/2013JC009512, 2014.

Valenti, D., Denaro, G., La Cognata, A., Spagnolo, B., Bonanno, A., Mazzola, S., Zgozi, S., and Aronica, S.: Picophytoplankton dynamics in noisy marine environment, Acta Phys. Pol. B, 43, 1227-1240, https://doi.org/10.5506/APhysPolB.43.1227, 2012.

Valenti, D., Denaro, G., Spagnolo, B., Conversano, F., and Brunet, C.: How diffusivity, thermocline and incident light intensity modulate the dynamics of deep chlorphyll maximum in Tyrrhenian Sea, PLoS ONE, 10(1), e0115468, https://doi.org/https://doi.org/10.1371/journal.pone.0115468, 2015.

Valenti, D., Denaro, G., Conversano, F., Brunet, C., Bonanno, A., Basilone, G., Mazzola, S., and Spagnolo, B.: The role of noise on the steady state distributions of phytoplankton populations, J. Stat. Mech., p. 054044, https://doi.org/10.1088/1742-5468/2016/05/054044, 2016a.

Valenti, D., Denaro, G., Spagnolo, B., Mazzola, S., Basilone, G., Conversano, F., Brunet, C., and Bonanno, A.: Stochastic models for phytoplankton dynamics in Mediterranean Sea, Ecol. Complex., 27, 84-103, https://doi.org/10.1016/j.ecocom.2015.06.001, 2016b.

Valenti, D., Giuffrida, A., Denaro, G., Pizzolato, N., Curcio, L., Mazzola, S., Basilone, G., Bonanno, A., and Spagnolo, B.: Noise Induced Phenomena in the Dynamics of Two Competing Species, Math. Model. Nat. Phenom., 11(5), 158-174, https://doi.org/https://doi.org/10.1051/mmnp/201611510, 2016c. 
Valenti, D., Denaro, G., Ferreri, R., Genovese, S., Aronica, S., Mazzola, S., Bonanno, A., Basilone, G., and Spagnolo, B.: Spatio-temporal dynamics of a planktonic system and chlorophyll distribution in a 2D spatial domain: matching model and data, Sci. Rep., 7, 220, https://doi.org/https://doi.org/10.1051/mmnp/201611510, 2017.

Van Rijn, L. C.: Principles of Fluid Flow and Surface Waves in Rivers, Estuaries, Seas and Oceans, Aqua Publications, 2011.

650 Veldhuis, M. J. W., Timmermans, K. R., Croot, P., and Van Der Wagt, B.: Picophytoplankton; a comparative study of their biochemical composition and photosynthetic properties, J. Sea Res., 53, 7-24, 2005.

Whalin, L., Kim, E., and Mason, R.: Factors influencing the oxidation, reduction, methylation and demethylation of mercury species in coastal waters, Mar. Chem., 107, 278-294, https://doi.org/10.1016/j.marchem.2007.04.002, 2007.

Zhang, Y., Jaeglé, L., and Thompson, L.: Natural biogeochemical cycle of mercury in a global three-dimensional ocean tracer model, Global Biogeochem. Cy., 28, GB004 814, https://doi.org/10.1002/2014GB004814, 2014. 
(a) $\mathrm{Hg}^{0}$ concentration (Station 1)

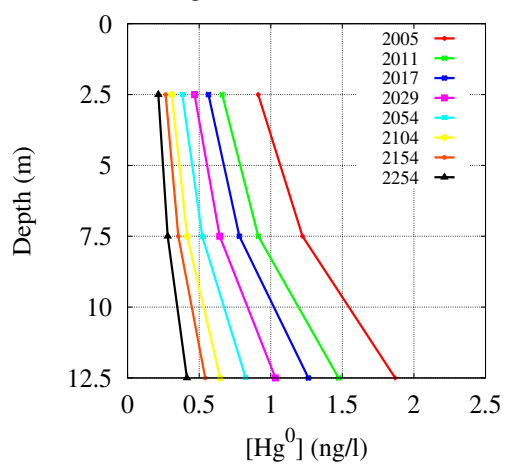

(d) $\mathrm{Hg}^{0}$ concentration (Station A9)

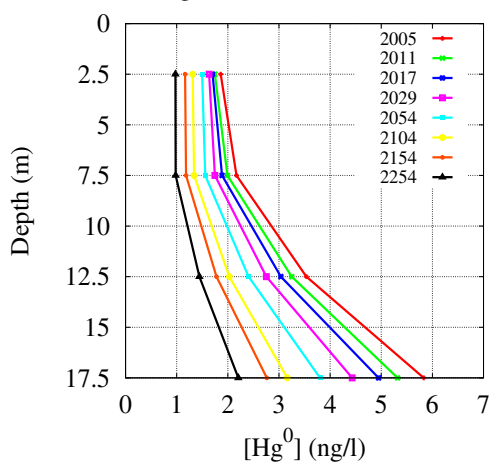

(b) $\mathrm{Hg}^{\mathrm{II}}$ concentration (Station 1)

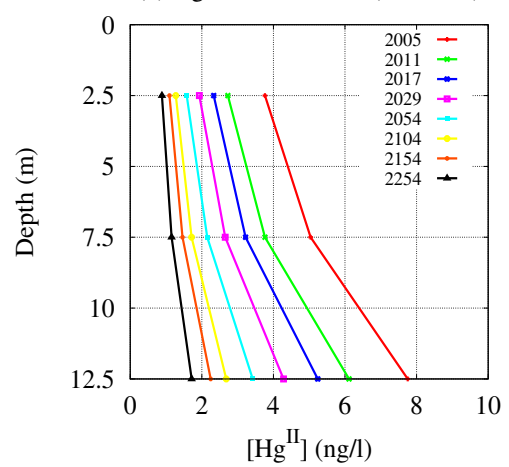

(e) $\mathrm{Hg}^{\mathrm{II}}$ concentration (Station A9)

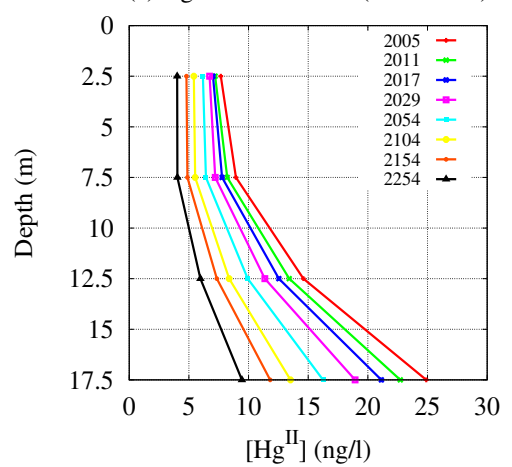

(c) $\mathrm{MeHg}$ concentration (Station 1)

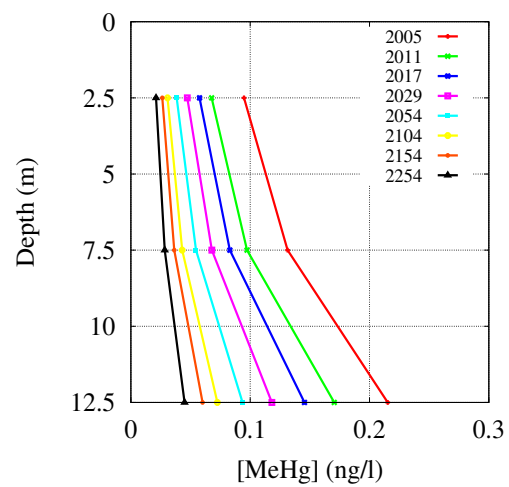

(f) $\mathrm{MeHg}$ concentration (Station A9)

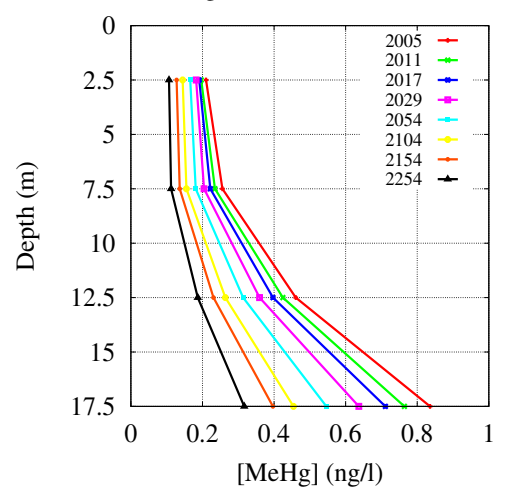

Figure S1. Spatio-temporal evolution of the three mercury species in seawater. Vertical profiles of $\left[\mathrm{Hg}^{0}\right]$ (panels a,d), $\left[H g^{I I}\right]($ panels b,e) and $[\mathrm{MeHg}]$ (panels c,f) are shown for the sites closest to station 1 (sampling May 2011) and station A9 (sampling October 2017). 

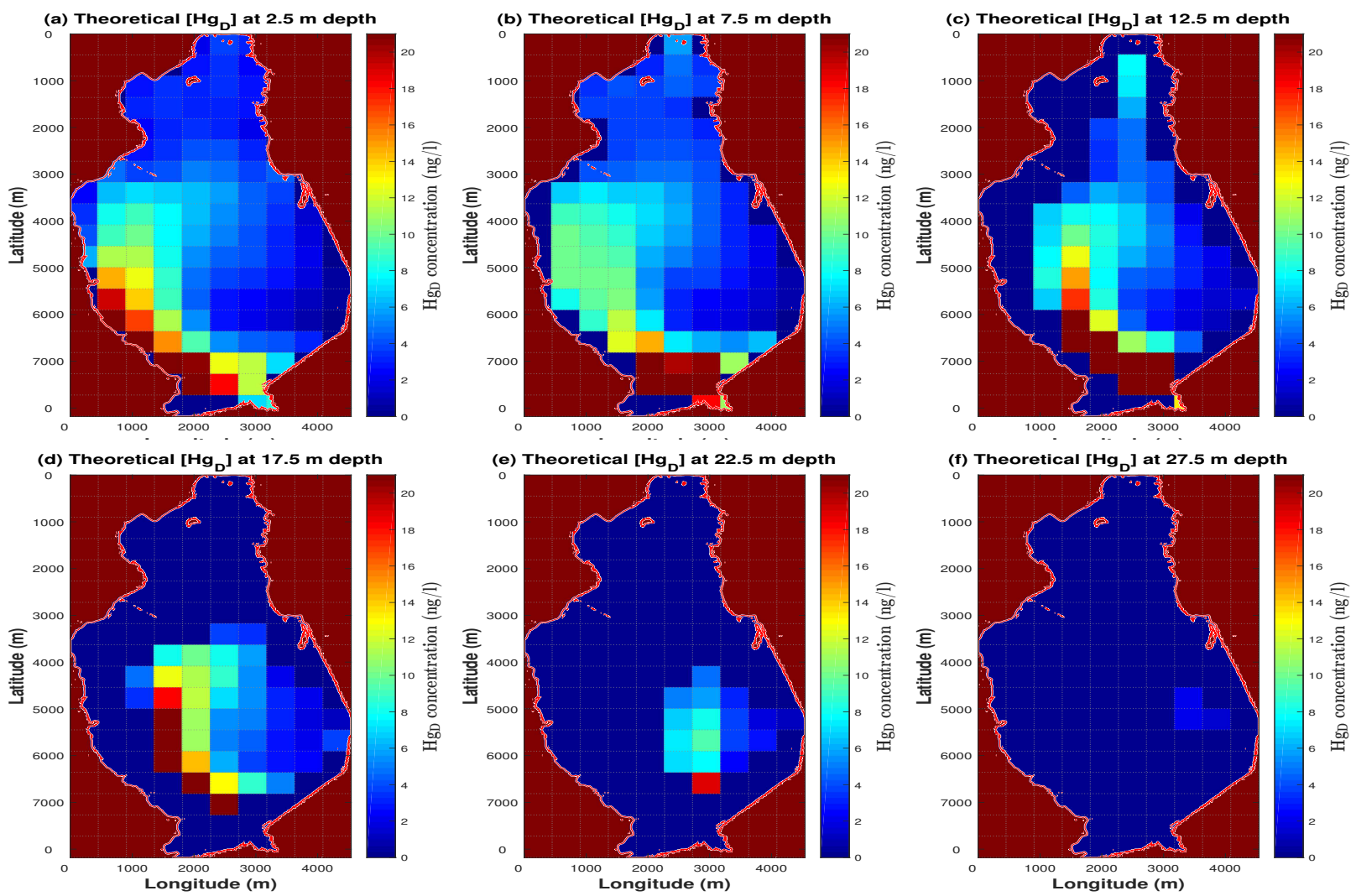

Figure S2. Theoretical distributions of the dissolved mercury concentration obtained by the model for the six different depths of the seawater compartment. The maps reproduce the spatial behaviour of the dissolved mercury concentration at the depths $2.5 \mathrm{~m}$ (panel a), $7.5 \mathrm{~m}$ (panel b), $12.5 \mathrm{~m}$ (panel c), $17.5 \mathrm{~m}$ (panel d), $22.5 \mathrm{~m}$ (panel e) and $27.5 \mathrm{~m}$ (panel f) during the sampling period of May 2011. 

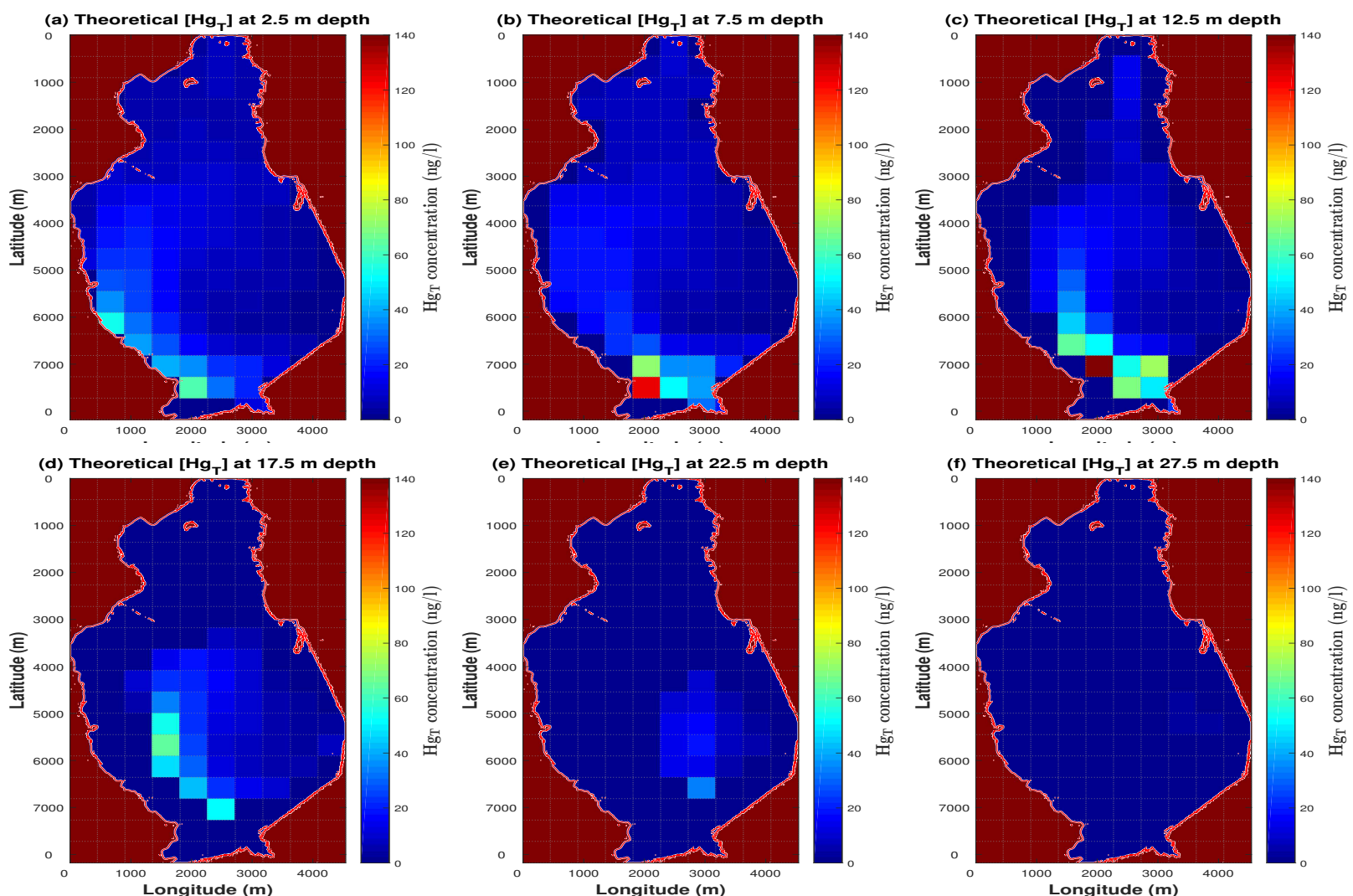

Figure S3. Theoretical distributions of the total mercury concentration obtained by the model for the six different depths of the seawater compartment. The maps reproduce the spatial behaviour of the total mercury concentration at the depths $2.5 \mathrm{~m}$ (panel a), $7.5 \mathrm{~m}$ (panel b), $12.5 \mathrm{~m}$ (panel c), $17.5 \mathrm{~m}$ (panel d), $22.5 \mathrm{~m}$ (panel e) and $27.5 \mathrm{~m}$ (panel f) during the sampling period of May 2011. 
(a) Experimental $\left[\mathrm{Hg}_{\mathrm{D}}\right]$ at the surface layer

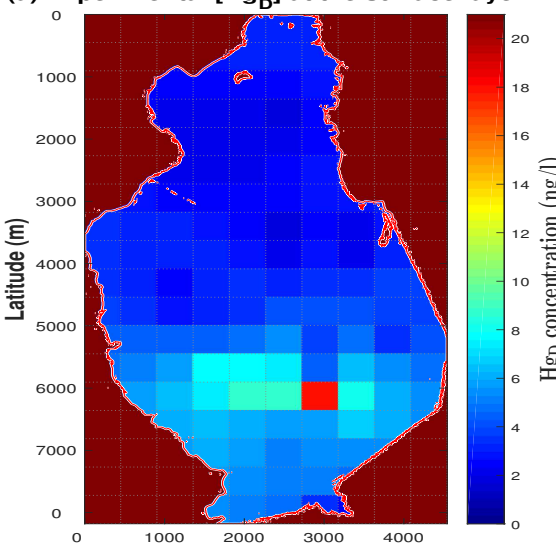

(c) Experimental $\left[\mathrm{Hg}_{\mathrm{D}}\right]$ at the intermediate layer

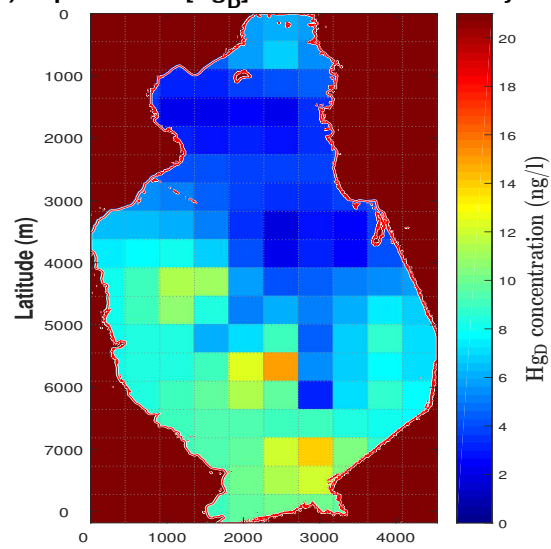

(e) Experimental $\left[\mathrm{Hg}_{\mathrm{D}}\right]$ at the bottom layer

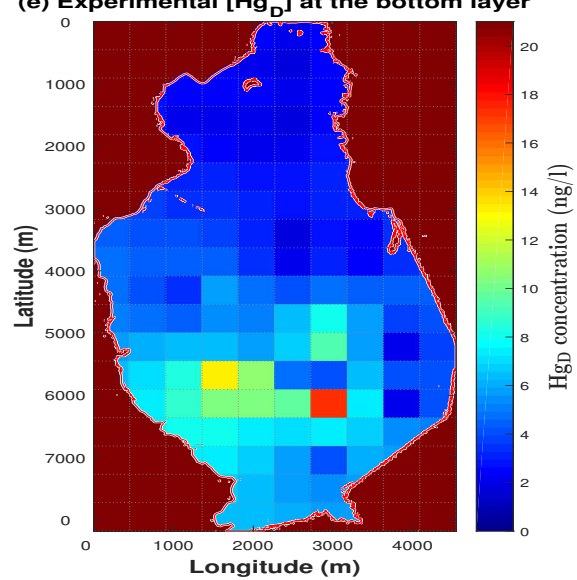

(b) Theoretical $\left[\mathrm{Hg}_{\mathrm{D}}\right]$ at the surface layer

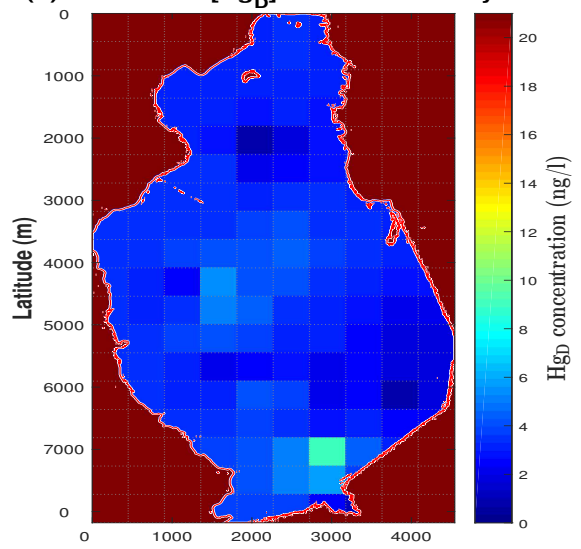

(d) Theoretical $\left[\mathrm{Hg}_{\mathrm{D}}\right]$ at the intermediate layer

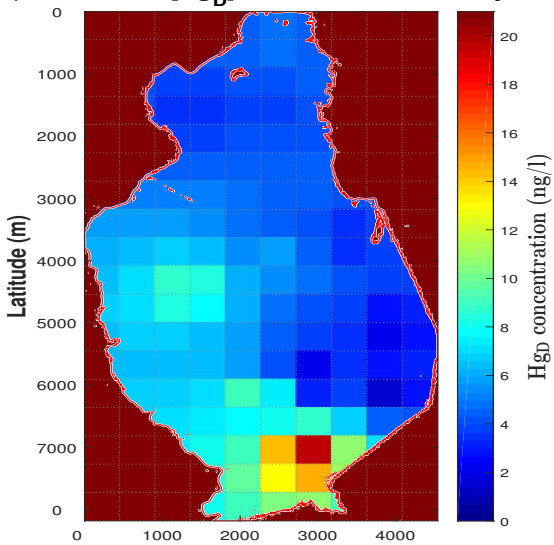

(f) Theoretical $\left[\mathrm{Hg}_{\mathrm{D}}\right]$ at the bottom layer

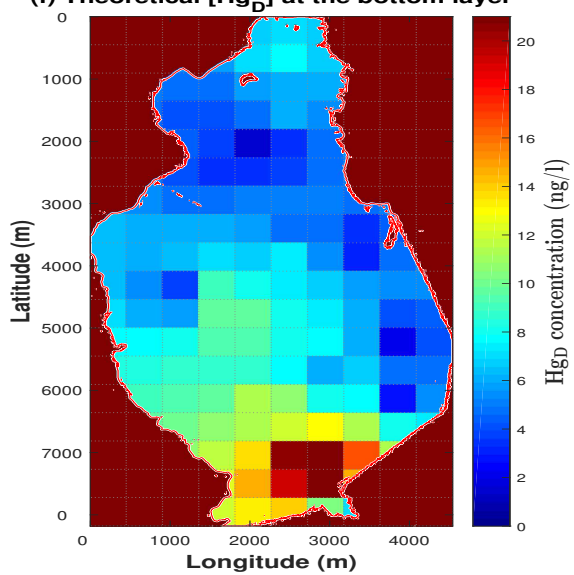

Figure S4. Comparison between the experimental data and the theoretical results for the dissolved mercury concentration. The maps reproduce the spatial distributions of the dissolved mercury concentration at surface layer (panels a, b), intermediate layer (panels c,d) and bottom layer (panels e,f) of the water column during the sampling period of May 2011. The spatial distributions are obtained by interpolating the experimental data collected in the Augusta Bay, and the theoretical results calculated by the model. 


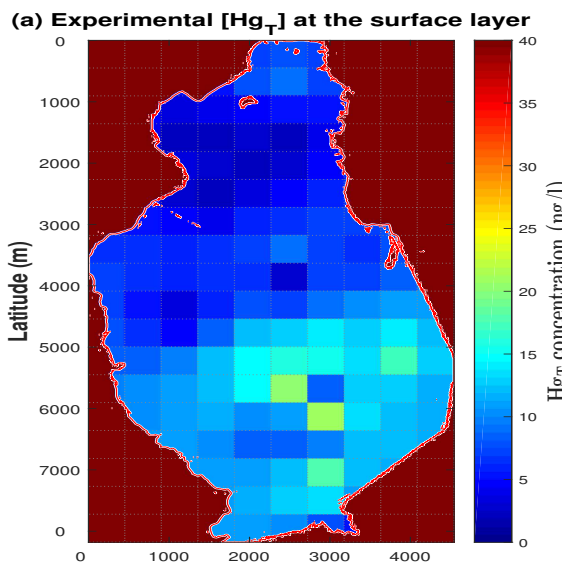

(c) Experimental $\left[\mathrm{Hg}_{\mathrm{T}}\right]$ at the intermediate layer

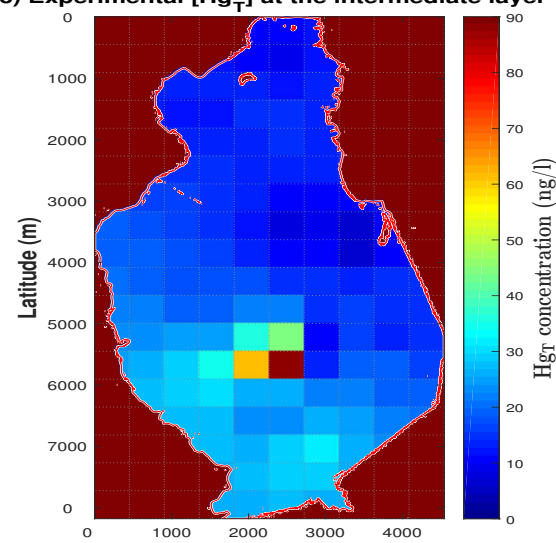

(e) Experimental $\left[\mathrm{Hg}_{\mathrm{T}}\right]$ at the bottom layer

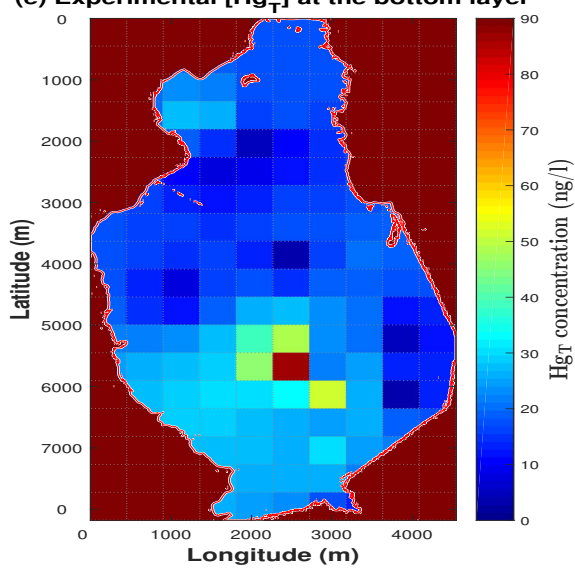

(b) Theoretical $\left[\mathrm{Hg}_{\mathrm{T}}\right]$ at the surface layer

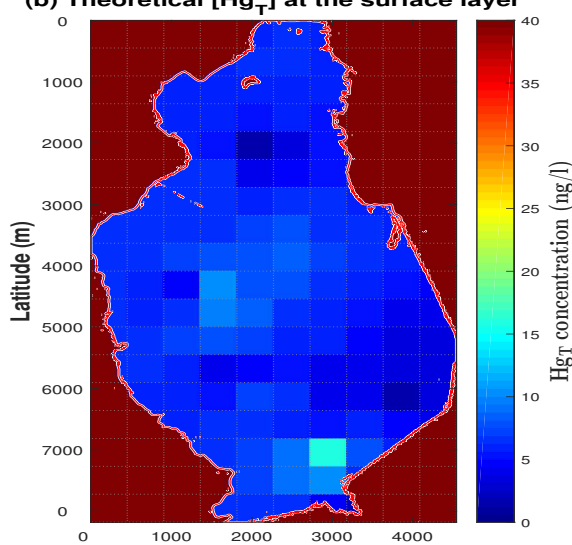

(d) Theoretical $\left[\mathrm{Hg}_{\mathrm{T}}\right]$ at the intermediate layer
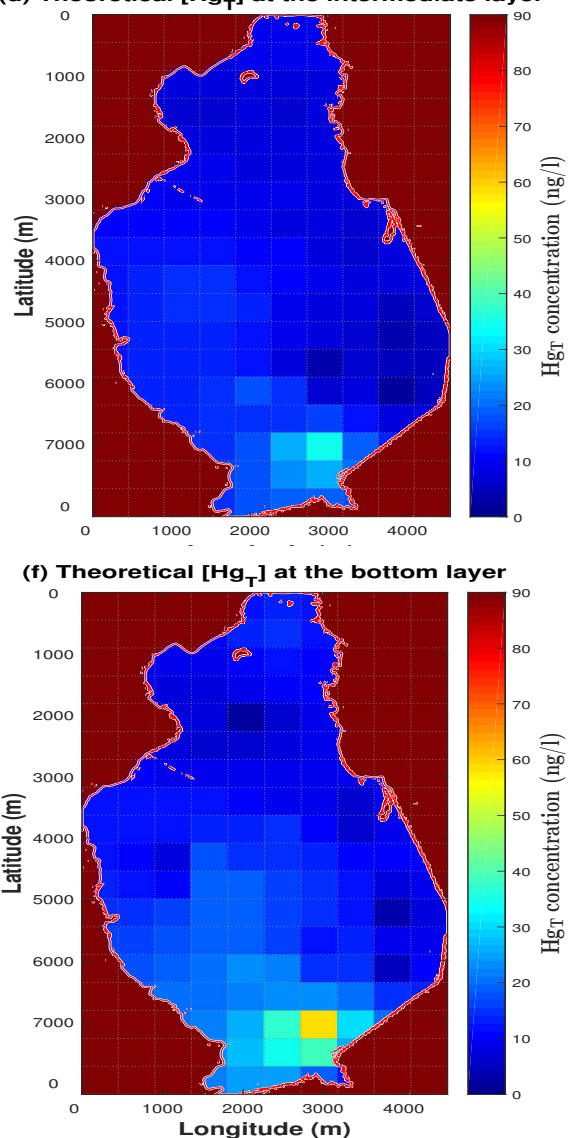

Figure S5. Comparison between the experimental data and the theoretical results for the total mercury concentration. The maps reproduce the spatial distributions of the total mercury concentration at surface layer (panels a, b), intermediate layer (panels c,d) and bottom layer (panels e,f) of the water column during the sampling period of May 2011. The spatial distributions are obtained by interpolating the experimental data collected in the Augusta Bay, and the theoretical results calculated by the model. 


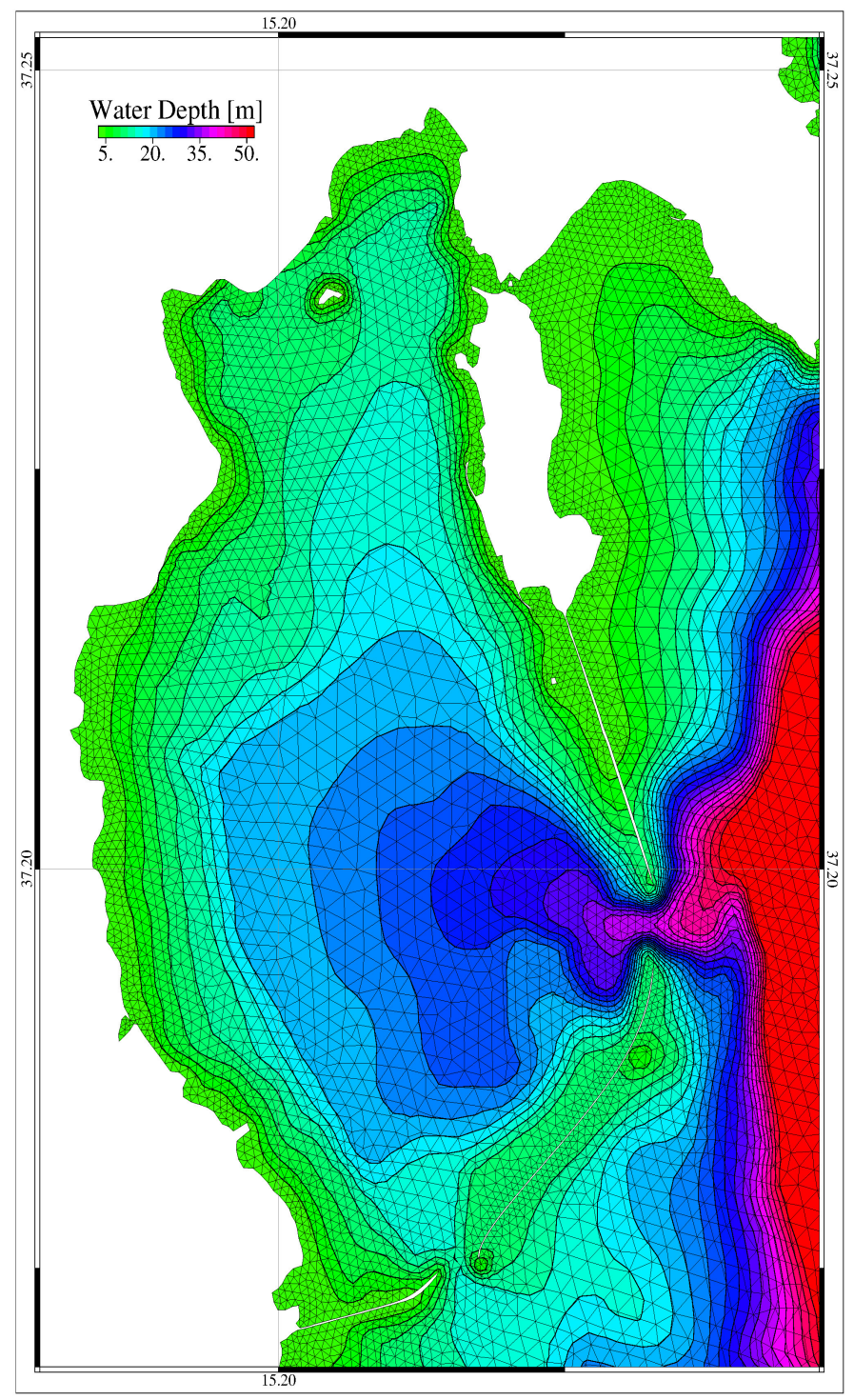

Figure S6. Zoom of the finite element mesh and bathymetry for the Augusta Bay and surrounding coastal area. 


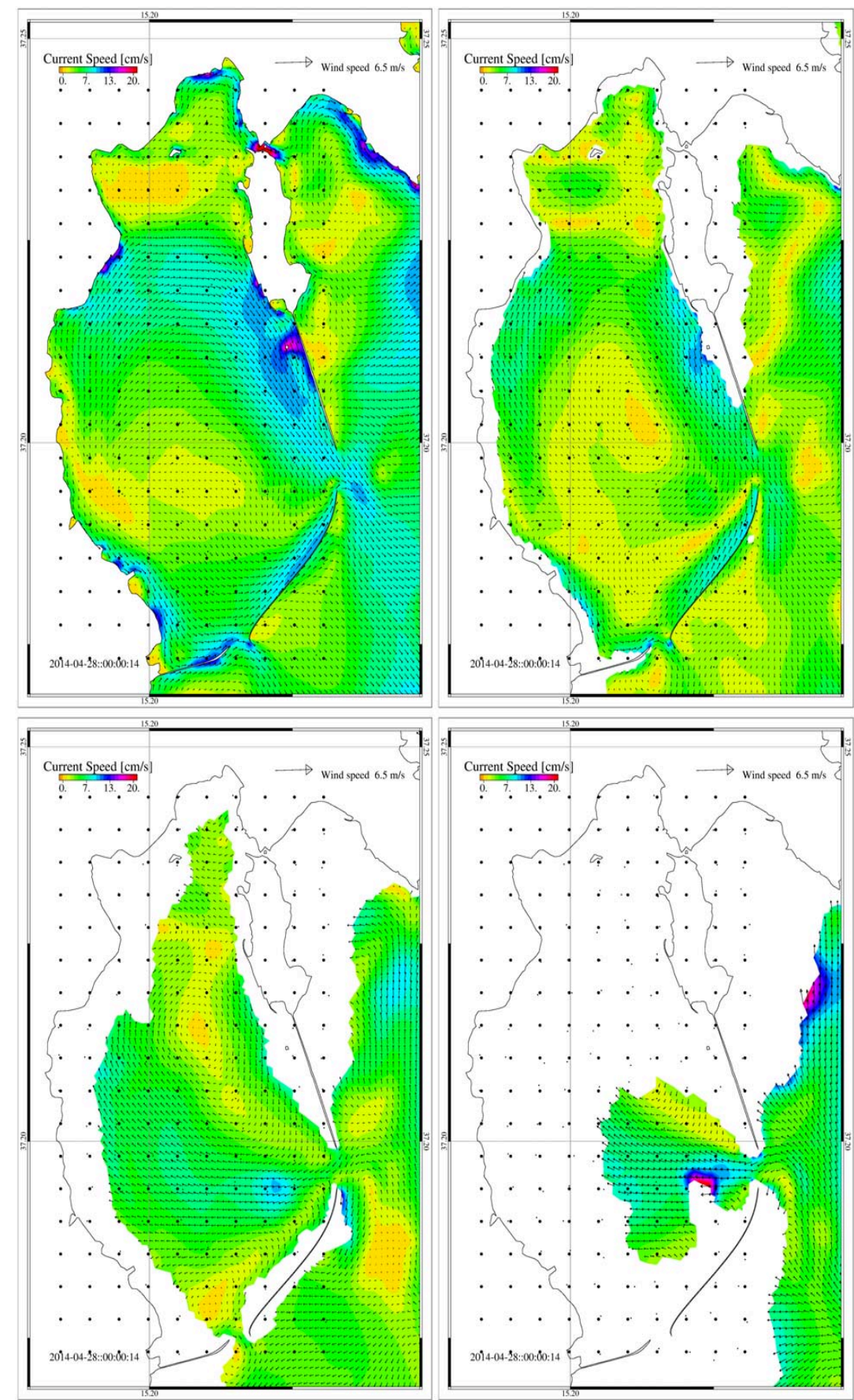

Figure S7. Velocity fields of marine currents computed by SHYFEM at different vertical levels in the Augusta harbour area. Black dots indicate the mesh points of the biogeochemical model domain. From left to right, the maps reproduce results obtained for the layers between 0-5 m, 5-10 m, 10-20 m e 20-30 m, respectively. 


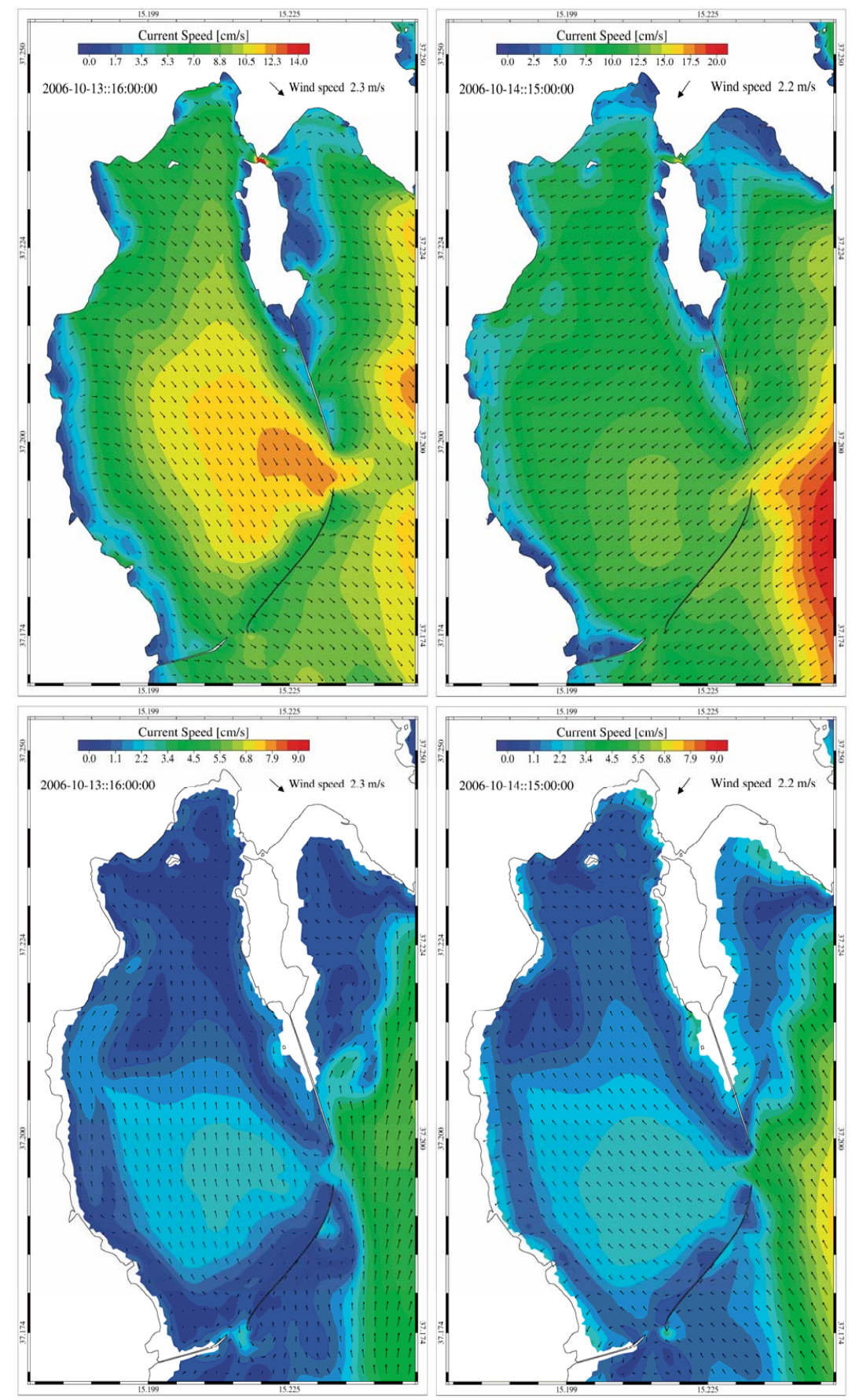

Figure S8. Current velocities at sea surface (upper panels) and deeper layers (bottom panels) computed at 16:00 of $13^{\text {th }}$ October 2006 (left panels) and at 15:00 of $14^{\text {th }}$ October 2006. 


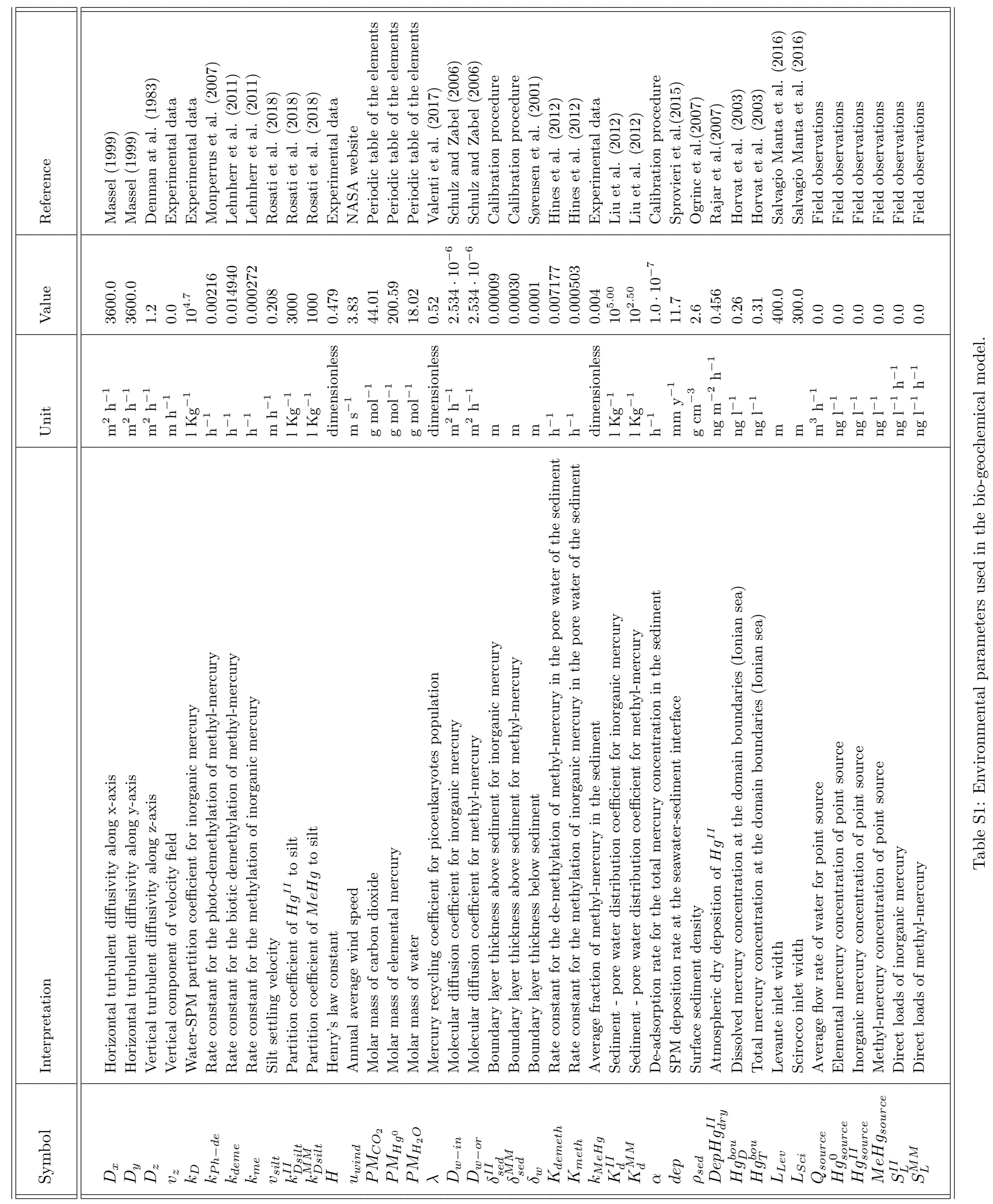




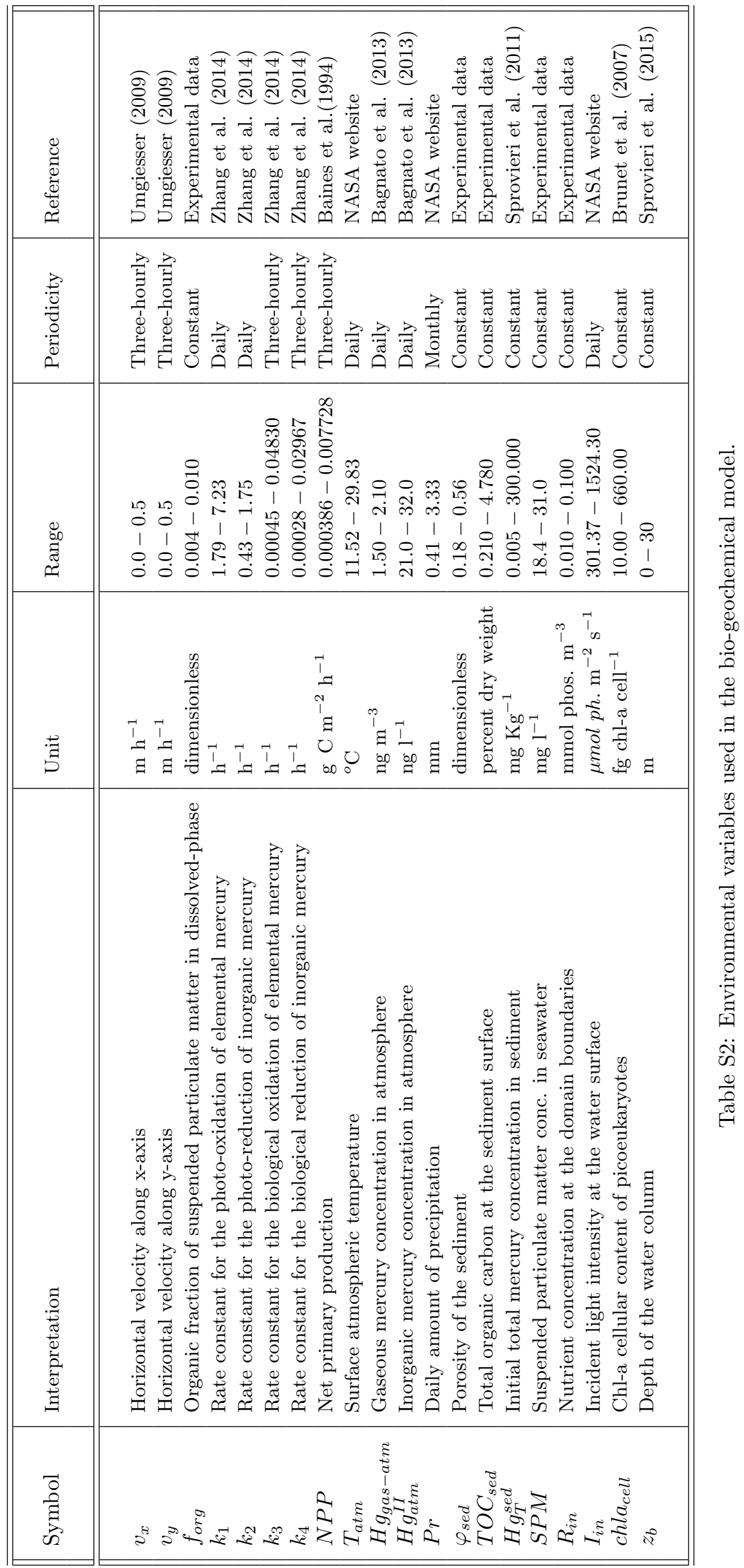




\begin{tabular}{|c|c|}
\hline 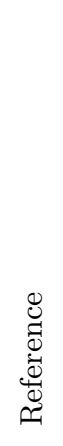 & 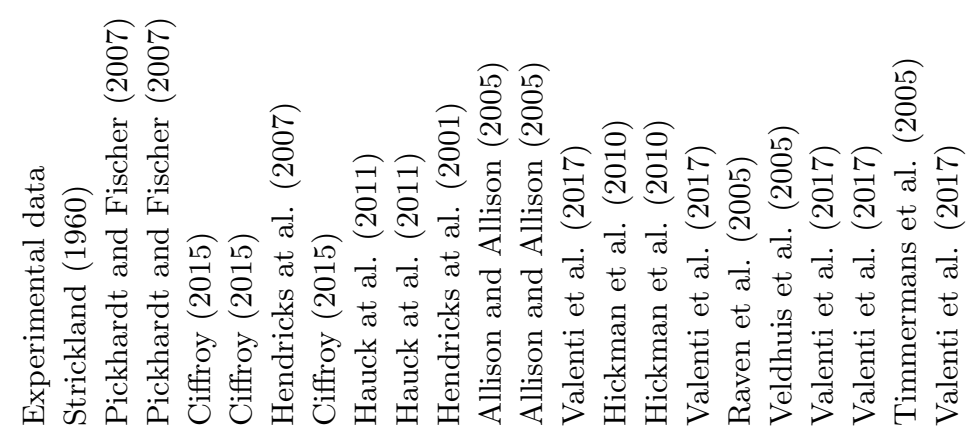 \\
\hline 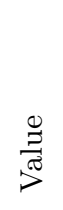 & 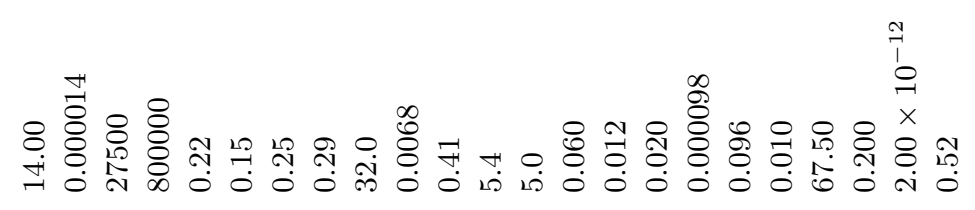 \\
\hline $\begin{array}{l}\vec{Z} \\
\vec{s}\end{array}$ & 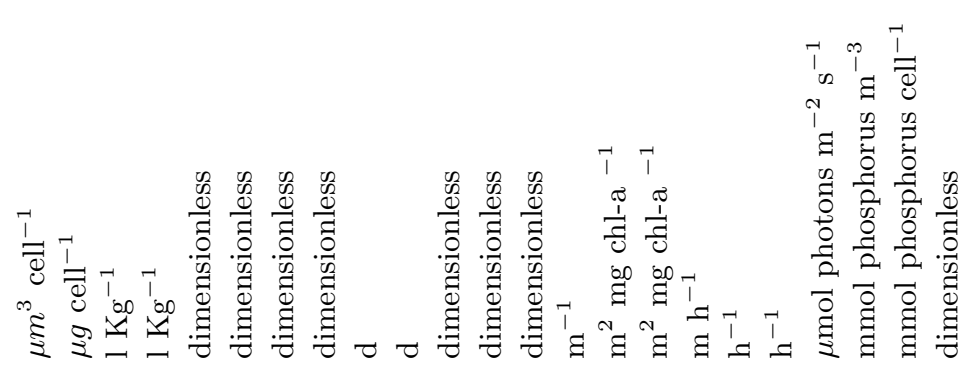 \\
\hline 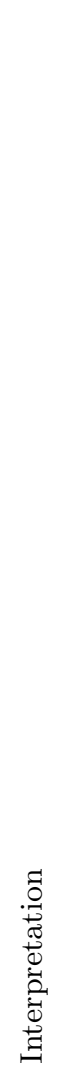 & 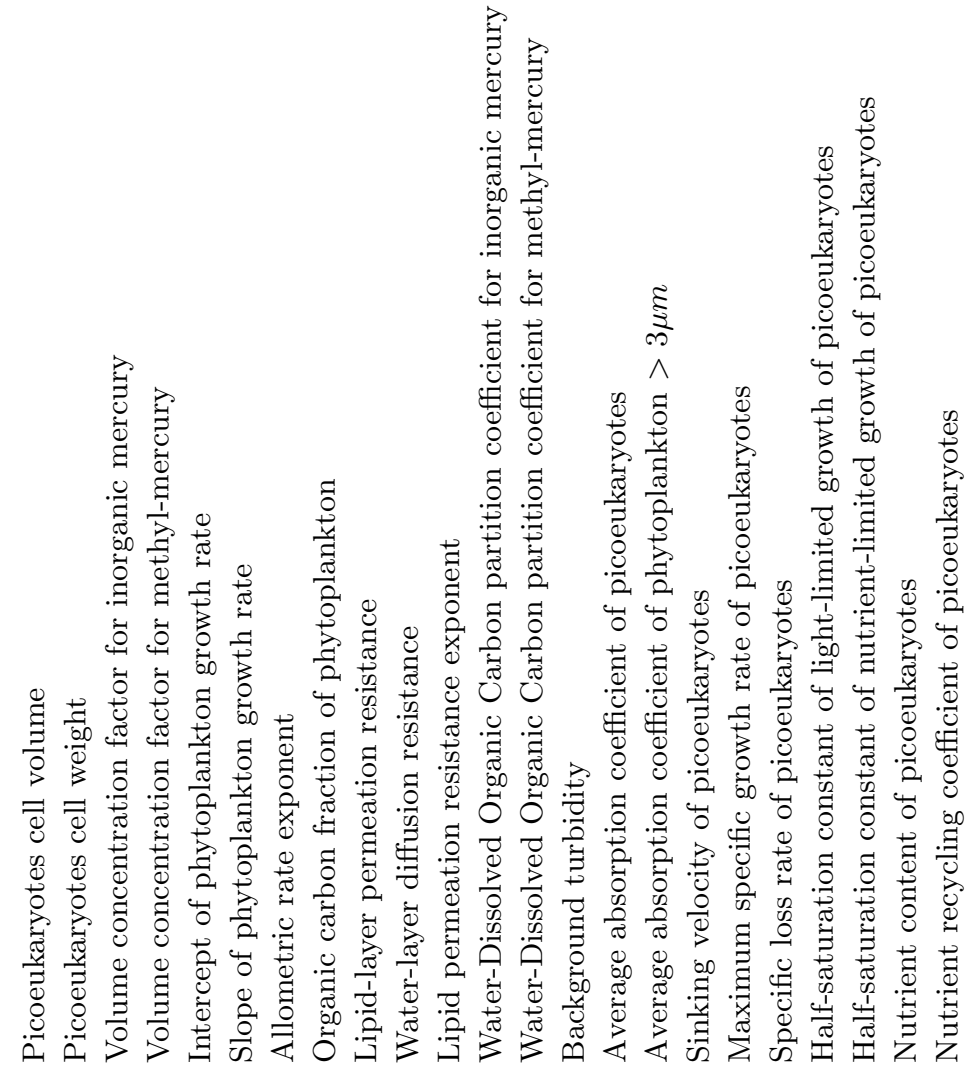 \\
\hline $\begin{array}{l}\text { ठ } \\
\text { है } \\
\text { के }\end{array}$ & 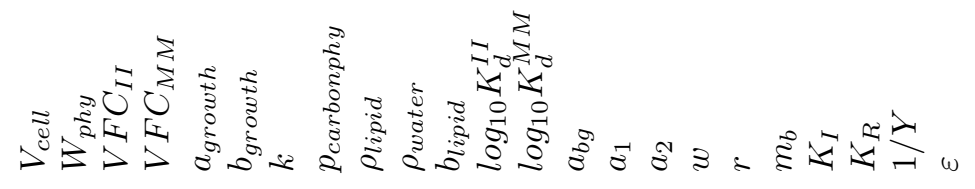 \\
\hline
\end{tabular}




\begin{tabular}{|l|l|l|l|l|}
\hline & \multicolumn{2}{|c|}{ Experimental data } & \multicolumn{2}{|c|}{ Theoretical results } \\
\hline Station & Latitude & Longitude & Latitude & Longitude \\
\hline 1 & 37.23987 & 15.20895 & 37.23949 & 15.21003 \\
\hline 2 & 37.23107 & 15.20865 & 37.23121 & 15.21003 \\
\hline 3 & 37.23105 & 15.19742 & 37.23121 & 15.19981 \\
\hline 4 & 37.22255 & 15.19837 & 37.22294 & 15.19981 \\
\hline 5 & 37.21415 & 15.20992 & 37.21466 & 15.21003 \\
\hline 6 & 37.21238 & 15.21960 & 37.21052 & 15.22024 \\
\hline 7 & 37.20963 & 15.20972 & 37.21052 & 15.21003 \\
\hline 10 & 37.20445 & 15.19772 & 37.20638 & 15.19981 \\
\hline 11 & 37.20015 & 15.20268 & 37.20224 & 15.20492 \\
\hline 12 & 37.19935 & 15.21425 & 37.19810 & 15.21514 \\
\hline 13 & 37.19905 & 15.22560 & 37.19810 & 15.22535 \\
\hline 15 & 37.19495 & 15.21528 & 37.193964 & 15.21514 \\
\hline 17 & 37.19493 & 15.20853 & 37.19396 & 15.21003 \\
\hline 20 & 37.18938 & 15.20723 & 37.18983 & 15.20492 \\
\hline 21 & 37.18813 & 15.20765 & 37.18983 & 15.21003 \\
\hline 23 & 37.19075 & 15.21442 & 37.18983 & 15.21514 \\
\hline 24 & 37.19057 & 15.22560 & 37.18983 & 15.22535 \\
\hline 25 & 37.18117 & 15.21388 & 37.18155 & 15.21514 \\
\hline 26 & 37.17183 & 15.21913 & 37.17327 & 15.22024 \\
\hline 27 & 37.19678 & 15.23880 & 37.19810 & 15.23046 \\
\hline$S T 1$ & 37.19352 & 15.21455 & 37.19396 & 15.21514 \\
\hline$S T 2$ & 37.21569 & 15.19763 & 37.21466 & 15.19981 \\
\hline$S T 3$ & 37.17957 & 15.20695 & 37.18155 & 15.20492 \\
\hline$S T 5$ & 37.20951 & 15.20962 & 37.21052 & 15.21003 \\
\hline$S T 6$ & 37.19470 & 15.21552 & 37.19396 & 15.21514 \\
\hline$S T 7$ & 37.18814 & 15.20757 & 37.18983 & 15.21003 \\
\hline$A 3$ & 37.22650 & 15.20633 & 37.22708 & 15.20492 \\
\hline$A 7$ & 37.20467 & 15.19467 & 37.20638 & 15.19470 \\
\hline$A 9$ & 37.19333 & 15.20233 & 37.19396 & 15.19981 \\
\hline$A 11$ & 37.18333 & 15.21350 & 37.18155 & 15.21514 \\
\hline
\end{tabular}

Table S4: Latitude and longitude of all sampling sites considered in the analysis of experimental data and theoretical results. 


\begin{tabular}{|c|c|c|c|c|c|c|c|c|c|}
\hline Stat. & Period & Depth $[\mathrm{m}]$ & $H g^{0}[n g / l]$ & $H g^{I I}[n g / l]$ & $\mathrm{MeHg}[\mathrm{ng} / \mathrm{l}]$ & $H g_{D}[n g / l]$ & $H g^{0} / H g_{D}$ & $H g^{I I} / H g_{D}$ & $\mathrm{MeHg} / \mathrm{Hg}_{D}$ \\
\hline 1 & $23-26 / 05 / 11$ & 2.50 & 0.661 & 2.727 & 0.068 & 3.456 & 0.191 & 0.789 & 0.020 \\
\hline 1 & $23-26 / 05 / 11$ & 7.50 & 0.912 & 3.763 & 0.097 & 4.774 & 0.191 & 0.788 & 0.021 \\
\hline 1 & $23-26 / 05 / 11$ & 12.50 & 1.473 & 6.113 & 0.171 & 7.757 & 0.190 & 0.788 & 0.022 \\
\hline 2 & $23-26 / 05 / 11$ & 2.50 & 0.590 & 2.434 & 0.061 & 3.085 & 0.191 & 0.789 & 0.020 \\
\hline 2 & $23-26 / 05 / 11$ & 7.50 & 0.689 & 2.840 & 0.072 & 3.601 & 0.191 & 0.789 & 0.020 \\
\hline 2 & $23-26 / 05 / 11$ & 12.50 & 1.181 & 4.909 & 0.138 & 6.228 & 0.190 & 0.788 & 0.022 \\
\hline 3 & $23-26 / 05 / 11$ & 2.50 & 0.630 & 2.600 & 0.061 & 3.291 & 0.191 & 0.790 & 0.019 \\
\hline 3 & $23-26 / 05 / 11$ & 7.50 & 0.751 & 3.110 & 0.076 & 3.937 & 0.191 & 0.790 & 0.019 \\
\hline 4 & $23-26 / 05 / 11$ & 2.50 & 0.662 & 2.733 & 0.063 & 3.458 & 0.192 & 0.790 & 0.018 \\
\hline 4 & $23-26 / 05 / 11$ & 7.50 & 0.733 & 3.033 & 0.075 & 3.841 & 0.190 & 0.790 & 0.020 \\
\hline 5 & $23-26 / 05 / 11$ & 2.50 & 0.764 & 3.152 & 0.072 & 3.988 & 0.192 & 0.790 & 0.018 \\
\hline 5 & $23-26 / 05 / 11$ & 7.50 & 0.813 & 3.357 & 0.079 & 4.249 & 0.191 & 0.790 & 0.019 \\
\hline 5 & $23-26 / 05 / 11$ & 12.50 & 0.910 & 3.792 & 0.103 & 4.805 & 0.189 & 0.789 & 0.022 \\
\hline 6 & $23-26 / 05 / 11$ & 2.50 & 0.653 & 2.696 & 0.063 & 3.412 & 0.191 & 0.790 & 0.019 \\
\hline 6 & $23-26 / 05 / 11$ & 7.50 & 0.590 & 2.436 & 0.057 & 3.083 & 0.191 & 0.790 & 0.019 \\
\hline 6 & $23-26 / 05 / 11$ & 12.50 & 0.430 & 1.791 & 0.046 & 2.267 & 0.190 & 0.790 & 0.020 \\
\hline 10 & $23-26 / 05 / 11$ & 2.50 & 1.486 & 6.132 & 0.151 & 7.769 & 0.191 & 0.789 & 0.020 \\
\hline 10 & $23-26 / 05 / 11$ & 7.50 & 1.941 & 8.009 & 0.219 & 10.169 & 0.191 & 0.788 & 0.021 \\
\hline 10 & $23-26 / 05 / 11$ & 17.50 & 2.396 & 9.896 & 0.291 & 12.583 & 0.190 & 0.787 & 0.023 \\
\hline 11 & $23-26 / 05 / 11$ & 2.50 & 1.014 & 4.183 & 0.098 & 5.295 & 0.191 & 0.790 & 0.019 \\
\hline 11 & $23-26 / 05 / 11$ & 7.50 & 1.173 & 4.838 & 0.118 & 6.129 & 0.192 & 0.789 & 0.019 \\
\hline 11 & $23-26 / 05 / 11$ & 17.50 & 2.186 & 9.081 & 0.272 & 11.539 & 0.189 & 0.787 & 0.024 \\
\hline 12 & $23-26 / 05 / 11$ & 2.50 & 0.663 & 2.738 & 0.060 & 3.461 & 0.192 & 0.791 & 0.017 \\
\hline 12 & $23-26 / 05 / 11$ & 12.50 & 0.769 & 3.173 & 0.076 & 4.018 & 0.191 & 0.790 & 0.019 \\
\hline 12 & $23-26 / 05 / 11$ & 22.50 & 1.495 & 6.374 & 0.198 & 8.069 & 0.185 & 0.790 & 0.025 \\
\hline 13 & $23-26 / 05 / 11$ & 2.50 & 0.343 & 1.414 & 0.031 & 1.788 & 0.192 & 0.791 & 0.017 \\
\hline 13 & $23-26 / 05 / 11$ & 17.50 & 0.369 & 1.523 & 0.038 & 1.930 & 0.191 & 0.789 & 0.020 \\
\hline 13 & $23-26 / 05 / 11$ & 27.50 & 0.291 & 1.209 & 0.034 & 1.534 & 0.190 & 0.788 & 0.022 \\
\hline 17 & $23-26 / 05 / 11$ & 2.50 & 0.531 & 2.192 & 0.049 & 2.772 & 0.192 & 0.790 & 0.018 \\
\hline 17 & $23-26 / 05 / 11$ & 12.50 & 0.704 & 2.903 & 0.074 & 3.681 & 0.191 & 0.789 & 0.020 \\
\hline 17 & $23-26 / 05 / 11$ & 22.50 & 1.365 & 5.685 & 0.176 & 7.226 & 0.189 & 0.787 & 0.024 \\
\hline 20 & $23-26 / 05 / 11$ & 2.50 & 1.023 & 4.222 & 0.109 & 5.354 & 0.191 & 0.789 & 0.020 \\
\hline 20 & $23-26 / 05 / 11$ & 12.50 & 2.342 & 9.675 & 0.286 & 12.303 & 0.190 & 0.786 & 0.023 \\
\hline 20 & $23-26 / 05 / 11$ & 17.50 & 2.676 & 11.161 & 0.352 & 14.189 & 0.189 & 0.786 & 0.025 \\
\hline 23 & $23-26 / 05 / 11$ & 2.50 & 0.378 & 1.561 & 0.037 & 1.976 & 0.191 & 0.790 & 0.019 \\
\hline 23 & $23-26 / 05 / 11$ & 12.50 & 0.524 & 2.161 & 0.057 & 2.742 & 0.191 & 0.788 & 0.021 \\
\hline 23 & $23-26 / 05 / 11$ & 22.50 & 1.392 & 6.024 & 0.199 & 7.615 & 0.183 & 0.791 & 0.026 \\
\hline 24 & $23-26 / 05 / 11$ & 2.50 & 0.164 & 0.676 & 0.016 & 0.856 & 0.192 & 0.790 & 0.019 \\
\hline 24 & $23-26 / 05 / 11$ & 7.50 & 0.218 & 0.898 & 0.023 & 1.139 & 0.191 & 0.788 & 0.020 \\
\hline 24 & $23-26 / 05 / 11$ & 17.50 & 0.474 & 2.039 & 0.064 & 2.577 & 0.184 & 0.791 & 0.025 \\
\hline 25 & $23-26 / 05 / 11$ & 2.50 & 2.205 & 9.096 & 0.254 & 11.555 & 0.191 & 0.787 & 0.022 \\
\hline 25 & $23-26 / 05 / 11$ & 7.50 & 3.900 & 16.088 & 0.483 & 20.471 & 0.190 & 0.786 & 0.024 \\
\hline 25 & $23-26 / 05 / 11$ & 12.50 & 7.804 & 32.755 & 1.075 & 41.634 & 0.187 & 0.787 & 0.026 \\
\hline 26 & $02 / 02 / 12$ & 2.50 & 0.162 & 0.671 & 0.022 & 0.855 & 0.189 & 0.785 & 0.026 \\
\hline 26 & $02 / 02 / 12$ & 7.50 & 1.079 & 4.522 & 0.152 & 5.753 & 0.188 & 0.786 & 0.026 \\
\hline 27 & $02 / 02 / 12$ & 2.50 & 0.016 & 0.068 & 0.002 & 0.086 & 0.186 & 0.791 & 0.023 \\
\hline 27 & $02 / 02 / 12$ & 12.50 & 0.452 & 1.859 & 0.050 & 2.361 & 0.192 & 0.787 & 0.021 \\
\hline 27 & $02 / 02 / 12$ & 22.50 & 0.349 & 1.472 & 0.044 & 1.865 & 0.187 & 0.789 & 0.024 \\
\hline 7 & $23-26 / 06 / 12$ & 2.50 & 0.879 & 3.629 & 0.083 & 4.591 & 0.192 & 0.790 & 0.018 \\
\hline 7 & $23-26 / 06 / 12$ & 12.50 & 1.098 & 4.533 & 0.115 & 5.746 & 0.191 & 0.789 & 0.020 \\
\hline 7 & $23-26 / 06 / 12$ & 17.50 & 1.452 & 6.034 & 0.172 & 7.658 & 0.190 & 0.788 & 0.022 \\
\hline 15 & $23-26 / 06 / 12$ & 2.50 & 0.387 & 1.596 & 0.036 & 2.019 & 0.192 & 0.790 & 0.018 \\
\hline 15 & $23-26 / 06 / 12$ & 12.50 & 0.298 & 1.228 & 0.032 & 1.558 & 0.191 & 0.788 & 0.021 \\
\hline 15 & $23-26 / 06 / 12$ & 22.50 & 1.022 & 4.487 & 0.152 & 5.661 & 0.180 & 0.793 & 0.027 \\
\hline 21 & $23-26 / 06 / 12$ & 2.50 & 0.574 & 2.367 & 0.057 & 2.998 & 0.191 & 0.790 & 0.019 \\
\hline 21 & $23-26 / 06 / 12$ & 17.50 & 1.269 & 5.233 & 0.152 & 6.654 & 0.191 & 0.786 & 0.023 \\
\hline 21 & $23-26 / 06 / 12$ & 22.50 & 1.637 & 6.818 & 0.211 & 8.666 & 0.189 & 0.787 & 0.024 \\
\hline$A 3$ & $19-23 / 10 / 17$ & 2.50 & 0.078 & 0.324 & 0.009 & 0.411 & 0.190 & 0.788 & 0.022 \\
\hline$A 3$ & $19-23 / 10 / 17$ & 12.50 & 0.139 & 0.588 & 0.018 & 0.745 & 0.187 & 0.789 & 0.024 \\
\hline$A 7$ & $19-23 / 10 / 17$ & 2.50 & 0.136 & 0.560 & 0.016 & 0.712 & 0.191 & 0.787 & 0.022 \\
\hline$A 7$ & $19-23 / 10 / 17$ & 17.50 & 0.040 & 0.203 & 0.007 & 0.250 & 0.160 & 0.812 & 0.028 \\
\hline$A 9$ & $19-23 / 10 / 17$ & 2.50 & 0.247 & 1.022 & 0.032 & 1.301 & 0.190 & 0.786 & 0.025 \\
\hline$A 9$ & $19-23 / 10 / 17$ & 17.50 & 1.278 & 6.668 & 0.232 & 8.178 & 0.156 & 0.815 & 0.029 \\
\hline$A 11$ & $19-23 / 10 / 17$ & 2.50 & 0.040 & 0.166 & 0.005 & 0.211 & 0.189 & 0.787 & 0.024 \\
\hline$A 11$ & $19-23 / 10 / 17$ & 12.50 & 1.437 & 6.916 & 0.241 & 8.594 & 0.167 & 0.805 & 0.028 \\
\hline
\end{tabular}

Table S5: Dissolved mercury concentration: comparison between experimental data and theoretical results for all sampling sites. The detection limit (d.l.) for mercury concentration is set at $1.9 \mathrm{ng} / \mathrm{l}$. 


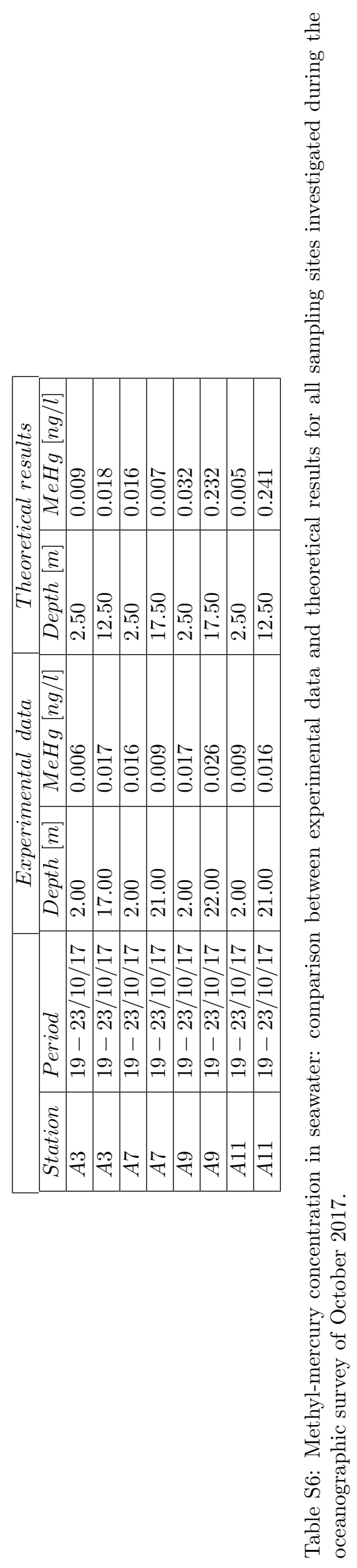




\begin{tabular}{|c|c|c|c|c|c|}
\hline & & Experin & ntal data & Theoreti & $l$ results \\
\hline Station & Period & Depth $[\mathrm{m}]$ & $H g_{D}[n g / l]$ & Depth $[m]$ & $H g_{D}[n g / l]$ \\
\hline 1 & $23-26 / 05 / 11$ & 1.40 & 3.200 & 2.50 & 3.456 \\
\hline 1 & $23-26 / 05 / 11$ & 6.20 & 6.700 & 7.50 & 4.774 \\
\hline 1 & $23-26 / 05 / 11$ & 11.20 & $\leq d . l$. & 12.50 & 7.757 \\
\hline 2 & $23-26 / 05 / 11$ & 2.21 & $\leq d . l$. & 2.50 & 3.085 \\
\hline 2 & $23-26 / 05 / 11$ & 6.71 & $\leq d . l$. & 7.50 & 3.601 \\
\hline 2 & $23-26 / 05 / 11$ & 10.65 & $\leq d . l$. & 12.50 & 6.228 \\
\hline 3 & $23-26 / 05 / 11$ & 2.26 & $\leq d . l$. & 2.50 & 3.291 \\
\hline 3 & $23-26 / 05 / 11$ & 4.60 & $\leq d . l$. & 2.50 & 3.291 \\
\hline 3 & $23-26 / 05 / 11$ & 8.40 & $\leq d . l$. & 7.50 & 3.937 \\
\hline 4 & $23-26 / 05 / 11$ & 0.10 & $\leq d . l$. & 2.50 & 3.458 \\
\hline 4 & $23-26 / 05 / 11$ & 3.12 & 3.200 & 7.50 & 3.458 \\
\hline 5 & $23-26 / 05 / 11$ & 1.00 & $\leq d . l$. & 2.50 & 3.988 \\
\hline 5 & $23-26 / 05 / 11$ & 9.20 & $\leq d . l$. & 7.50 & 4.249 \\
\hline 5 & $23-26 / 05 / 11$ & 15.88 & $\leq d . l$. & 12.50 & 4.805 \\
\hline 6 & $23-26 / 05 / 11$ & 1.98 & $\leq d . l$. & 2.50 & 3.412 \\
\hline 6 & $23-26 / 05 / 11$ & 6.74 & $\leq d . l$. & 7.50 & 3.083 \\
\hline 6 & $23-26 / 05 / 11$ & 13.54 & $\leq d . l$. & 12.50 & 2.267 \\
\hline 10 & $23-26 / 05 / 11$ & 1.00 & 3.200 & 2.50 & 7.769 \\
\hline 10 & $23-26 / 05 / 11$ & 9.50 & 14.300 & 7.50 & 10.169 \\
\hline 10 & $23-26 / 05 / 11$ & 19.20 & 7.300 & 17.50 & 12.583 \\
\hline 11 & $23-26 / 05 / 11$ & 1.42 & $\leq d . l$. & 2.50 & 5.295 \\
\hline 11 & $23-26 / 05 / 11$ & 10.00 & $\leq d . l$. & 7.50 & 6.129 \\
\hline 11 & $23-26 / 05 / 11$ & 18.15 & 3.300 & 17.50 & 11.539 \\
\hline 12 & $23-26 / 05 / 11$ & 1.63 & 3.200 & 2.50 & 3.461 \\
\hline 12 & $23-26 / 05 / 11$ & 13.50 & 3.200 & 12.50 & 4.018 \\
\hline 12 & $23-26 / 05 / 11$ & 23.41 & 11.800 & 22.50 & 8.069 \\
\hline 13 & $23-26 / 05 / 11$ & 2.40 & 3.200 & 2.50 & 1.788 \\
\hline 13 & $23-26 / 05 / 11$ & 16.90 & 8.900 & 17.50 & 1.930 \\
\hline 13 & $23-26 / 05 / 11$ & 29.30 & $\leq d . l$. & 27.50 & 1.534 \\
\hline 17 & $23-26 / 05 / 11$ & 1.20 & 7.500 & 2.50 & 2.772 \\
\hline 17 & $23-26 / 05 / 11$ & 11.45 & 19.800 & 12.50 & 3.681 \\
\hline 17 & $23-26 / 05 / 11$ & 21.90 & $\leq d . l$. & 22.50 & 7.226 \\
\hline 20 & $23-26 / 05 / 11$ & 0.50 & $\overline{12.600}$ & 2.50 & 5.354 \\
\hline 20 & $23-26 / 05 / 11$ & 11.30 & 14.600 & 12.50 & 12.303 \\
\hline 20 & $23-26 / 05 / 11$ & 16.45 & 14.600 & 17.50 & 14.189 \\
\hline 23 & $23-26 / 05 / 11$ & 2.40 & 21.300 & 2.50 & 1.976 \\
\hline 23 & $23-26 / 05 / 11$ & 11.24 & $\leq d . l$. & 12.50 & 2.742 \\
\hline 23 & $23-26 / 05 / 11$ & 20.55 & 20.300 & 22.50 & 7.615 \\
\hline 24 & $23-26 / 05 / 11$ & 1.00 & 6.000 & 2.50 & 0.856 \\
\hline 24 & $23-26 / 05 / 11$ & 9.40 & 8.900 & 7.50 & 1.139 \\
\hline 24 & $23-26 / 05 / 11$ & 16.30 & $\leq d . l$. & 17.50 & 2.577 \\
\hline 25 & $23-26 / 05 / 11$ & 1.60 & $\overline{6.000}$ & 2.50 & 11.555 \\
\hline 25 & $23-26 / 05 / 11$ & 7.30 & 14.600 & 7.50 & 20.471 \\
\hline 25 & $23-26 / 05 / 11$ & 12.70 & 3.200 & 12.50 & 41.634 \\
\hline 26 & $02 / 02 / 12$ & 2.00 & $\leq d . l$ & 2.50 & 0.855 \\
\hline 26 & $02 / 02 / 12$ & 8.00 & 5.550 & 7.50 & 5.753 \\
\hline 27 & $02 / 02 / 12$ & 2.00 & $\leq d . l$. & 2.50 & 0.086 \\
\hline 27 & $02 / 02 / 12$ & 11.50 & $\leq d . l$. & 12.50 & 2.361 \\
\hline 27 & $02 / 02 / 12$ & 27.00 & 3.550 & 22.50 & 1.865 \\
\hline 7 & $23-26 / 06 / 12$ & 1.00 & $\leq d . l$. & 2.50 & 4.591 \\
\hline 7 & $23-26 / 06 / 12$ & 13.50 & $\leq d . l$. & 12.50 & 5.746 \\
\hline 7 & $23-26 / 06 / 12$ & 21.00 & $\leq d . l$. & 17.50 & 7.658 \\
\hline 15 & $23-26 / 06 / 12$ & 1.00 & 2.550 & 2.50 & 2.019 \\
\hline 15 & $23-26 / 06 / 12$ & 11.50 & 4.950 & 12.50 & 1.558 \\
\hline 15 & $23-26 / 06 / 12$ & 26.00 & 2.350 & 22.50 & 5.661 \\
\hline 21 & $23-26 / 06 / 12$ & 1.00 & $\leq d . l$. & 2.50 & 2.998 \\
\hline 21 & $23-26 / 06 / 12$ & 16.00 & 6.350 & 17.50 & 6.654 \\
\hline 21 & $23-26 / 06 / 12$ & 22.00 & $\leq d . l$. & 22.50 & 8.666 \\
\hline$A 3$ & $19-23 / 10 / 17$ & 2.00 & $\leq d . l$. & 2.50 & 0.411 \\
\hline$A 3$ & $19-23 / 10 / 17$ & 17.00 & $\leq d . l$. & 12.50 & 0.745 \\
\hline$A 7$ & $19-23 / 10 / 17$ & 2.00 & $\leq d . l$. & 2.50 & 0.712 \\
\hline$A 7$ & $19-23 / 10 / 17$ & 21.00 & $\leq d . l$. & 17.50 & 0.250 \\
\hline$A 9$ & $19-23 / 10 / 17$ & 2.00 & $\overline{9.032}$ & 2.50 & 1.301 \\
\hline$A 9$ & $19-23 / 10 / 17$ & 22.00 & 17.785 & 17.50 & 8.178 \\
\hline$A 11$ & $19-23 / 10 / 17$ & 2.00 & $\leq d . l$. & 2.50 & 0.211 \\
\hline$A 11$ & $19-23 / 10 / 17$ & 21.00 & 6.545 & 12.50 & 8.594 \\
\hline
\end{tabular}

Table S7: Dissolved mercury concentration: comparison between experimental data and theoretical results for all sampling sites. The detection limit (d.l.) for mercury concentration is set at $1.9 \mathrm{ng} / \mathrm{l}$. 


\begin{tabular}{|c|c|c|c|c|c|}
\hline & & \multicolumn{2}{|c|}{ Experimental data } & \multicolumn{2}{|c|}{ Theoretical results } \\
\hline Station & Period & Depth $[m]$ & $H g_{T}[n g / l]$ & Depth $[\mathrm{m}]$ & $H g_{T}[n g / l]$ \\
\hline 1 & $23-26 / 05 / 11$ & 1.40 & 9.171 & 2.50 & 6.610 \\
\hline 1 & $23-26 / 05 / 11$ & 6.20 & 9.171 & 7.50 & 8.951 \\
\hline 1 & $23-26 / 05 / 11$ & 11.20 & 17.771 & 12.50 & 14.262 \\
\hline 2 & $23-26 / 05 / 11$ & 2.21 & $\leq d . l$ & 2.50 & 5.982 \\
\hline 2 & $23-26 / 05 / 11$ & 6.71 & $\overline{14.871}$ & 7.50 & 6.788 \\
\hline 2 & $23-26 / 05 / 11$ & 10.65 & 17.671 & 12.50 & 11.415 \\
\hline 3 & $23-26 / 05 / 11$ & 2.26 & $\leq d . l$. & 2.50 & 6.367 \\
\hline 3 & $23-26 / 05 / 11$ & 4.60 & $\overline{11.971}$ & 2.50 & 6.367 \\
\hline 3 & $23-26 / 05 / 11$ & 8.40 & 29.971 & 7.50 & 7.422 \\
\hline 4 & $23-26 / 05 / 11$ & 0.10 & $\leq d . l$ & 2.50 & 6.694 \\
\hline 4 & $23-26 / 05 / 11$ & 3.12 & 6.271 & 2.50 & 6.694 \\
\hline 5 & $23-26 / 05 / 11$ & 1.00 & 9.171 & 2.50 & 7.731 \\
\hline 5 & $23-26 / 05 / 11$ & 9.20 & 7.071 & 7.50 & 8.013 \\
\hline 5 & $23-26 / 05 / 11$ & 15.88 & 17.671 & 12.50 & 8.816 \\
\hline 6 & $23-26 / 05 / 11$ & 1.98 & 6.271 & 2.50 & 6.365 \\
\hline 6 & $23-26 / 05 / 11$ & 6.74 & 3.371 & 7.50 & 5.756 \\
\hline 6 & $23-26 / 05 / 11$ & 13.54 & 20.571 & 12.50 & 4.242 \\
\hline 10 & $23-26 / 05 / 11$ & 1.00 & 4.271 & 2.50 & 15.422 \\
\hline 10 & $23-26 / 05 / 11$ & 9.50 & 15.871 & 7.50 & 16.797 \\
\hline 10 & $23-26 / 05 / 11$ & 19.20 & 14.871 & 17.50 & 23.441 \\
\hline 11 & $23-26 / 05 / 11$ & 1.42 & 14.871 & 2.50 & 10.010 \\
\hline 11 & $23-26 / 05 / 11$ & 10.00 & 14.871 & 7.50 & 15.914 \\
\hline 11 & $23-26 / 05 / 11$ & 18.15 & 23.471 & 17.50 & 22.821 \\
\hline 12 & $23-26 / 05 / 11$ & 1.63 & 17.671 & 2.50 & 6.312 \\
\hline 12 & $23-26 / 05 / 11$ & 13.50 & 3.371 & 12.50 & 7.686 \\
\hline 12 & $23-26 / 05 / 11$ & 23.41 & 19.271 & 22.50 & 15.922 \\
\hline 13 & $23-26 / 05 / 11$ & 2.40 & 17.671 & 2.50 & 3.241 \\
\hline 13 & $23-26 / 05 / 11$ & 16.90 & 12.671 & 17.50 & 3.635 \\
\hline 13 & $23-26 / 05 / 11$ & 29.30 & 3.371 & 27.50 & 2.903 \\
\hline 17 & $23-26 / 05 / 11$ & 1.20 & 26.271 & 2.50 & 5.006 \\
\hline 17 & $23-26 / 05 / 11$ & 11.45 & 129.271 & 12.50 & 7.280 \\
\hline 17 & $23-26 / 05 / 11$ & 21.90 & 127.071 & 22.50 & 14.969 \\
\hline 20 & $23-26 / 05 / 11$ & 0.50 & 12.600 & 2.50 & 9.620 \\
\hline 20 & $23-26 / 05 / 11$ & 11.30 & 23.500 & 12.50 & 24.837 \\
\hline 20 & $23-26 / 05 / 11$ & 16.45 & 28.200 & 17.50 & 30.291 \\
\hline 23 & $23-26 / 05 / 11$ & 2.40 & 23.371 & 2.50 & 3.541 \\
\hline 23 & $23-26 / 05 / 11$ & 11.24 & 20.571 & 12.50 & 5.027 \\
\hline 23 & $23-26 / 05 / 11$ & 20.55 & 57.771 & 22.50 & 14.272 \\
\hline 24 & $23-26 / 05 / 11$ & 1.00 & 11.971 & 2.50 & 1.533 \\
\hline 24 & $23-26 / 05 / 11$ & 9.40 & 18.671 & 7.50 & 2.055 \\
\hline 24 & $23-26 / 05 / 11$ & 16.30 & 2.271 & 17.50 & 4.759 \\
\hline 25 & $23-26 / 05 / 11$ & 1.60 & 22.571 & 2.50 & 20.562 \\
\hline 25 & $23-26 / 05 / 11$ & 7.30 & 31.971 & 7.50 & 36.186 \\
\hline 25 & $23-26 / 05 / 11$ & 12.70 & 34.871 & 12.50 & 73.210 \\
\hline 26 & $02 / 02 / 12$ & 2.00 & 4.554 & 2.50 & 1.507 \\
\hline 26 & $02 / 02 / 12$ & 8.00 & 11.054 & 7.50 & 10.160 \\
\hline 27 & $02 / 02 / 12$ & 2.00 & 4.554 & 2.50 & 0.155 \\
\hline 27 & $02 / 02 / 12$ & 11.50 & 4.804 & 12.50 & 4.674 \\
\hline 27 & $02 / 02 / 12$ & 27.00 & 6.104 & 22.50 & 3.494 \\
\hline 7 & $23-26 / 06 / 12$ & 1.00 & 1.854 & 2.50 & 8.724 \\
\hline 7 & $23-26 / 06 / 12$ & 13.50 & 9.854 & 12.50 & 10.841 \\
\hline 7 & $23-26 / 06 / 12$ & 21.00 & 1.750 & 17.50 & 14.529 \\
\hline 15 & $23-26 / 06 / 12$ & 1.00 & 5.954 & 2.50 & 3.647 \\
\hline 15 & $23-26 / 06 / 12$ & 11.50 & 8.554 & 12.50 & 2.952 \\
\hline 15 & $23-26 / 06 / 12$ & 26.00 & 15.687 & 22.50 & 11.097 \\
\hline 21 & $23-26 / 06 / 12$ & 1.00 & 1.020 & 2.50 & 5.383 \\
\hline 21 & $23-26 / 06 / 12$ & 16.00 & 14.854 & 17.50 & 9.908 \\
\hline 21 & $23-26 / 06 / 12$ & 22.00 & 18.090 & 22.50 & 17.042 \\
\hline$A 3$ & $19-23 / 10 / 17$ & 2.00 & $\leq d . l$. & 2.50 & 0.801 \\
\hline$A 3$ & $19-23 / 10 / 17$ & 17.00 & $\leq d . l$. & 12.50 & 1.365 \\
\hline$A 7$ & $19-23 / 10 / 17$ & 2.00 & $\leq d . l$. & 2.50 & 1.429 \\
\hline$A 7$ & $19-23 / 10 / 17$ & 21.00 & $\leq d . l$. & 17.50 & 0.470 \\
\hline$A 9$ & $19-23 / 10 / 17$ & 2.00 & $\overline{12.182}$ & 2.50 & 2.337 \\
\hline$A 9$ & $19-23 / 10 / 17$ & 22.00 & 25.132 & 17.50 & 18.615 \\
\hline$A 11$ & $19-23 / 10 / 17$ & 2.00 & $\leq d . l$. & 2.50 & 0.375 \\
\hline$A 11$ & $19-23 / 10 / 17$ & 21.00 & 12.482 & 12.50 & 15.275 \\
\hline
\end{tabular}

Table S8: Total mercury concentration: comparison between experimental data and theoretical results for all sampling sites. The detection limit (d.l.) for mercury concentration is set at $1.9 \mathrm{ng} / \mathrm{l}$. 


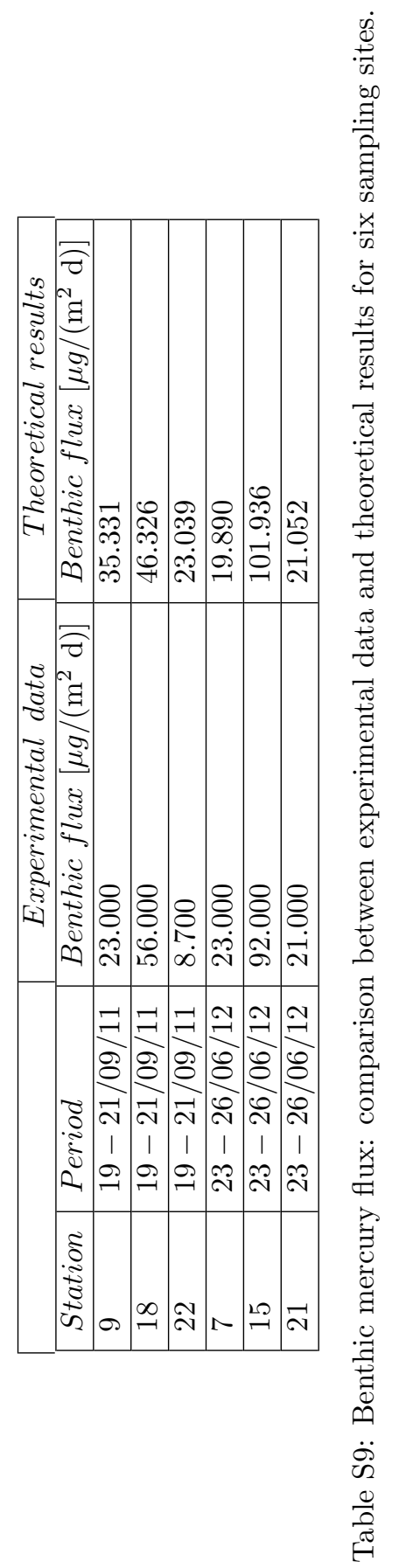




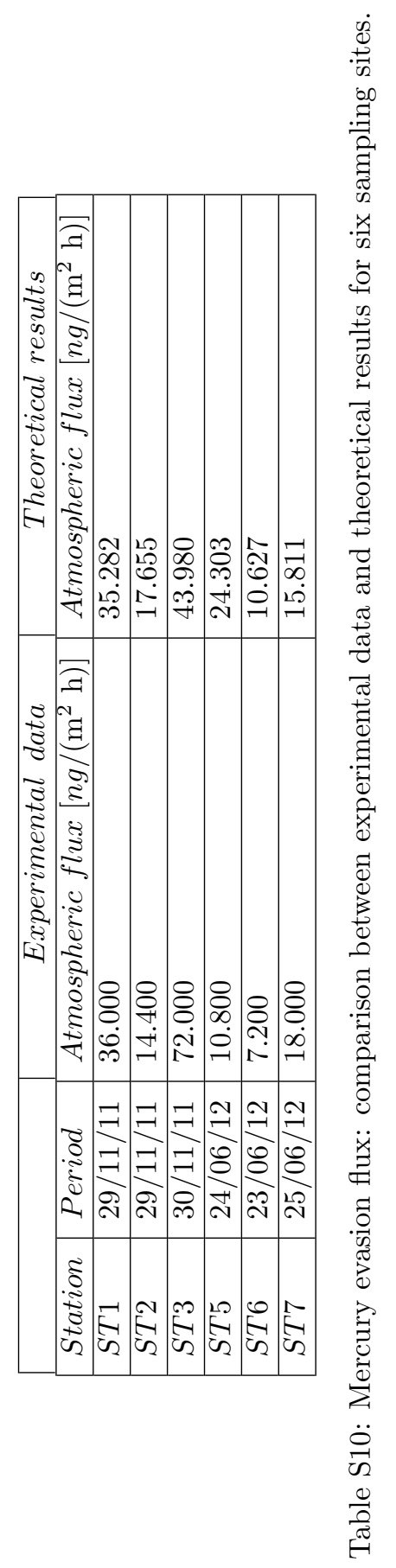




\begin{tabular}{|c|c|c|c|c|}
\hline Symbol & Interpretation & Year & Unit & Value \\
\hline $\begin{array}{l}O_{\text {Lev}_{1}} \\
O_{S c i_{1}} \\
O_{1} \\
B_{1} \\
V_{1} \\
S_{1} \\
D_{1}\end{array}$ & $\begin{array}{l}\text { Total mercury outflow from the Levante inlet to the open sea } \\
\text { Total mercury outflow from the Scirocco inlet to the open sea } \\
\text { Total mercury outflow from the basin to the open sea } \\
\text { Dissolved mercury release from the sediment of the basin } \\
\text { Gaseous elemental mercury evasion from the basin into the atmosphere } \\
\text { Amount of mercury recycled for scavenging within the Augusta basin } \\
\text { Total mercury recycled within the Augusta basin }\end{array}$ & $\begin{array}{l}2005 \\
2005 \\
2005 \\
2005 \\
2005 \\
2005 \\
2005\end{array}$ & $\begin{array}{l}\text { Kmol/year } \\
\text { Kmol/year } \\
\text { Kmol/year } \\
\text { Kmol/year } \\
\text { Kmol/year } \\
\text { Kmol/year } \\
\text { Kmol/year }\end{array}$ & $\begin{array}{l}0.060 \\
0.119 \\
0.179 \\
3.110 \\
0.022 \\
0.088 \\
2.911\end{array}$ \\
\hline $\begin{array}{l}\mathrm{O}_{\text {Lev }} \\
\mathrm{OSci}_{2} \\
\mathrm{O}_{2} \\
\mathrm{~B}_{2} \\
\mathrm{~V}_{2} \\
\mathrm{~S}_{2} \\
\mathrm{D}_{2}\end{array}$ & $\begin{array}{l}\text { Total mercury outflow from the Levante inlet to the open sea } \\
\text { Total mercury outflow from the Scirocco inlet to the open sea } \\
\text { Total mercury outflow from the basin to the open sea } \\
\text { Dissolved mercury release from the sediment of the basin } \\
\text { Gaseous elemental mercury evasion from the basin into the atmosphere } \\
\text { Amount of mercury recycled for scavenging within the Augusta basin } \\
\text { Total mercury recycled within the Augusta basin }\end{array}$ & $\begin{array}{l}2011 \\
2011 \\
2011 \\
2011 \\
2011 \\
2011 \\
2011\end{array}$ & $\begin{array}{l}\text { Kmol/year } \\
\text { Kmol/year } \\
\text { Kmol/year } \\
\text { Kmol/year } \\
\text { Kmol/year } \\
\text { Kmol/year } \\
\text { Kmol/year }\end{array}$ & $\begin{array}{l}0.050 \\
0.082 \\
0.132 \\
2.648 \\
0.019 \\
0.072 \\
2.499\end{array}$ \\
\hline $\begin{array}{l}O_{\text {Lev }_{3}} \\
\mathrm{OSci}_{3} \\
\mathrm{O}_{3} \\
B_{3} \\
V_{3} \\
S_{3} \\
D_{3}\end{array}$ & $\begin{array}{l}\text { Total mercury outflow from the Levante inlet to the open sea } \\
\text { Total mercury outflow from the Scirocco inlet to the open sea } \\
\text { Total mercury outflow from the basin to the open sea } \\
\text { Dissolved mercury release from the sediment of the basin } \\
\text { Gaseous elemental mercury evasion from the basin into the atmosphere } \\
\text { Amount of mercury recycled for scavenging within the Augusta basin } \\
\text { Total mercury recycled within the Augusta basin }\end{array}$ & $\begin{array}{l}2017 \\
2017 \\
2017 \\
2017 \\
2017 \\
2017 \\
2017\end{array}$ & $\begin{array}{l}\text { Kmol/year } \\
\text { Kmol/year } \\
\text { Kmol/year } \\
\text { Kmol/year } \\
\text { Kmol/year } \\
\text { Kmol/year } \\
\text { Kmol/year }\end{array}$ & $\begin{array}{l}0.045 \\
0.069 \\
0.114 \\
2.451 \\
0.018 \\
0.066 \\
2.321\end{array}$ \\
\hline $\begin{array}{l}O_{\text {Lev }_{4}} \\
O_{S c i} \\
O_{4} \\
B_{4} \\
V_{4} \\
S_{4} \\
D_{4}\end{array}$ & $\begin{array}{l}\text { Total mercury outflow from the Levante inlet to the open sea } \\
\text { Total mercury outflow from the Scirocco inlet to the open sea } \\
\text { Total mercury outflow from the basin to the open sea } \\
\text { Dissolved mercury release from the sediment of the basin } \\
\text { Gaseous elemental mercury evasion from the basin into the atmosphere } \\
\text { Amount of mercury recycled for scavenging within the Augusta basin } \\
\text { Total mercury recycled within the Augusta basin }\end{array}$ & $\begin{array}{l}2054 \\
2054 \\
2054 \\
2054 \\
2054 \\
2054 \\
2054\end{array}$ & $\begin{array}{l}\text { Kmol/year } \\
\text { Kmol/year } \\
\text { Kmol/year } \\
\text { Kmol/year } \\
\text { Kmol/year } \\
\text { Kmol/year } \\
\text { Kmol/year }\end{array}$ & $\begin{array}{l}0.032 \\
0.050 \\
0.082 \\
1.978 \\
0.014 \\
0.050 \\
1.884\end{array}$ \\
\hline $\begin{array}{l}O_{\text {Lev}_{5}} \\
O_{S c i_{5}} \\
O_{5} \\
B_{5} \\
V_{5} \\
S_{5} \\
D_{5}\end{array}$ & $\begin{array}{l}\text { Total mercury outflow from the Levante inlet to the open sea } \\
\text { Total mercury outflow from the Scirocco inlet to the open sea } \\
\text { Total mercury outflow from the basin to the open sea } \\
\text { Dissolved mercury release from the sediment of the basin } \\
\text { Gaseous elemental mercury evasion from the basin into the atmosphere } \\
\text { Amount of mercury recycled for scavenging within the Augusta basin } \\
\text { Total mercury recycled within the Augusta basin }\end{array}$ & $\begin{array}{l}2104 \\
2104 \\
2104 \\
2104 \\
2104 \\
2104 \\
2104\end{array}$ & $\begin{array}{l}\text { Kmol/year } \\
\text { Kmol/year } \\
\text { Kmol/year } \\
\text { Kmol/year } \\
\text { Kmol/year } \\
\text { Kmol/year } \\
\text { Kmol/year }\end{array}$ & $\begin{array}{l}0.027 \\
0.042 \\
0.069 \\
1.742 \\
0.012 \\
0.043 \\
1.663\end{array}$ \\
\hline $\begin{array}{l}O_{\text {evv }_{6}} \\
O_{S_{\text {ci }}} \\
O_{6} \\
B_{6} \\
V_{6} \\
S_{6} \\
D_{6}\end{array}$ & $\begin{array}{l}\text { Total mercury outflow from the Levante inlet to the open sea } \\
\text { Total mercury outflow from the Scirocco inlet to the open sea } \\
\text { Total mercury outflow from the basin to the open sea } \\
\text { Dissolved mercury release from the sediment of the basin } \\
\text { Gaseous elemental mercury evasion from the basin into the atmosphere } \\
\text { Amount of mercury recycled for scavenging within the Augusta basin } \\
\text { Total mercury recycled within the Augusta basin }\end{array}$ & $\begin{array}{l}2254 \\
2254 \\
2254 \\
2254 \\
2254 \\
2254 \\
2254\end{array}$ & $\begin{array}{l}\text { Kmol/year } \\
\text { Kmol/year } \\
\text { Kmol/year } \\
\text { Kmol/year } \\
\text { Kmol/year } \\
\text { Kmol/year } \\
\text { Kmol/year }\end{array}$ & $\begin{array}{l}0.018 \\
0.034 \\
0.052 \\
1.385 \\
0.009 \\
0.032 \\
1.326\end{array}$ \\
\hline $\begin{array}{l}A \\
A D\end{array}$ & $\begin{array}{l}\text { Input of dissolved mercury from anthropogenic activities } \\
\text { Atmospheric mercury deposition }\end{array}$ & & $\begin{array}{l}\text { Kmol/year } \\
\text { Kmol/year }\end{array}$ & $\begin{array}{l}0.000 \\
2.210 \cdot 10^{-3}\end{array}$ \\
\hline
\end{tabular}

Table S11: Mass balance of mercury in the Augusta basin simulated for six different years $(2005,2011$, 2017, 2054, 2104, and 2254). 


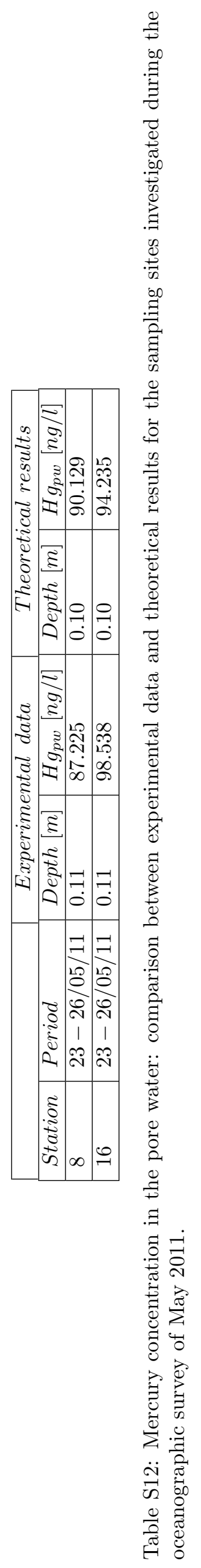

